The author(s) shown below used Federal funds provided by the U.S. Department of Justice and prepared the following final report:

Document Title: Identifying Mental Health Treatment Needs Among Serious Institutionalized Delinquents Using Paper-and Pencil Screening Instruments, Final Report

Author(s): $\quad$ Rudy Haapanen Ph.D. ; Hans Steiner M.D.

Document No.: 202980

Date Received: $\quad 11 / 21 / 2003$

Award Number: $\quad$ 98-CE-VX-0024

This report has not been published by the U.S. Department of Justice. To provide better customer service, NCJRS has made this Federallyfunded grant final report available electronically in addition to traditional paper copies.

Opinions or points of view expressed are those of the author(s) and do not necessarily reflect the official position or policies of the U.S. Department of Justice. 


\begin{abstract}
Identifying Mental Health Treatment Needs Among Serious Institutionalized Delinquents Using Paper-and-Pencil Screening Instruments
\end{abstract}

Grant \# 98-CE-VX-0024

Rudy Haapanen, Ph.D.

California Youth Authority

Hans Steiner, M.D.

Stanford University School of Medicine

Purpose: The present research explored the usefulness of the California Youth Authority's current mental health and substance abuse screening process for identifying wards for whom mental health intervention is needed and for profiling the aggregate mental health treatment needs of incoming wards. The screening process utilizes a self-report assessment battery, which includes:

1. Achenbach Child Behavior Checklist--Youth Self Report (YSR)

2. Massachusetts Youth Screening Instrument: Second Version (MAYSI)

3. Weinberger Adjustment Inventory (WAI)

4. Drug Experience Questionnaire (DEQ)

Research Subjects: Included in the study were 836 wards (664 males and 172 females) who first entered the CYA during particular periods.

Methods: Wards who completed screening questionnaires were followed to determine whether they were subsequently placed in mental health programs, prescribed medications used to treat serious mental health problems, and/or identified by staff as requiring these services (placed on a waiting list, identified as having suicidal tendencies, etc.). Analyses focused on the association between elevations on scales within the screening battery and these indicators of mental health service need. The WAI, which does not focus specifically on mental health problems, was not included in these analyses.

Results: The number and percent of the CYA sample that were identified as needing mental health intervention was substantial. Overall, $38.2 \%$ of the sample had at least one indicator of mental health intervention or identification. A much larger percentage of females $(66.3 \%)$ than of males (30.9\%) were identified. Both the MAYSI Scales and YSR Scales were related to validation criteria in expected ways. Wards with elevated scores on these instruments were more likely to come to the attention of mental health personnel. Of the two instruments, the MAYSI performed better. Elevations on MAYSI scales were better predictors of later mental health intervention than were elevations on similar YSR scales. The vast majority of wards (over 70\%) had DEQ scores indicating substance abuse problems. This information did not aid in predicting mental health intervention. Likewise, prior criminal behavior did not improve predictions.

Conclusions: Both the MAYSI and the YSR appeared to provide results that could aid in identifying male wards who would later require mental health services while incarcerated. Neither instrument was particularly helpful for predicting intervention for female wards. Further, both the MAYSI and YSR appeared to understate the extent of mental health problems for females. Of the two instruments, the MAYSI appeared to be a more useful screening instrument. 


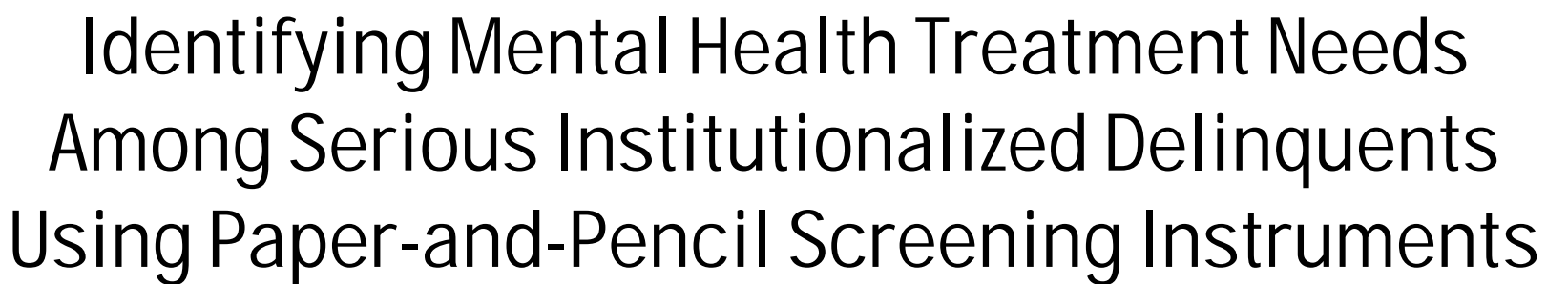

Final Report

To the

National Institute of Justice

California Youth Authority

Stanford University School of Medicine

July 2003

This document is a research report submitted to the U.S. Department of Justice. This report has not been published by the Department. Opinions or points of view expressed are those of the author(s) and do not necessarily reflect the official position or policies of the U.S. Department of Justice.

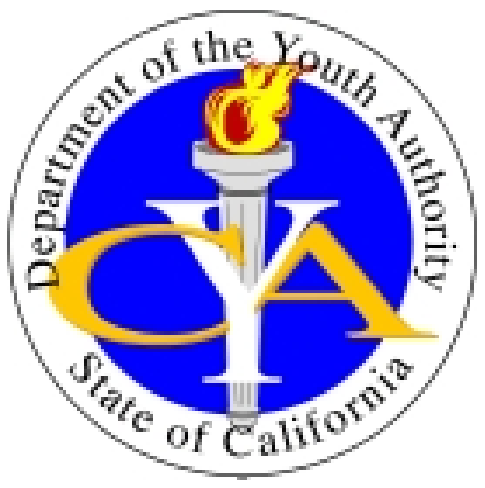




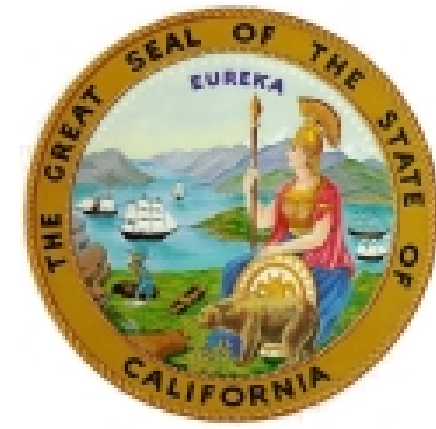

\section{Department}

\section{of the}

\section{Youth Authority}

\section{MISSION AND VALUES}

THE MISSION OF THE YOUTH AUTHORITY is to protect the public from criminal activity by providing education, training, and treatment services for youthful offenders committed by the courts; directing these offenders to participate in community and victim restoration; and assisting local justice agencies with their efforts to control crime and delinquency; and encouraging the development of state and local programs to prevent crime and delinquency.

In order to enhance our ability to accomplish our mission, we have a shared set of values. WE $\boldsymbol{V A L U E}$ :

\section{JERRY L. HARPER \\ Director}

\section{RICHARD KAI}

Chief Deputy Director

MICHAEL GALLEGOS, Deputy Director (A)
Institutions and Camps Branch

KIP LOWE, Deputy Director (A)

Institutions and Camps Branch

JUDY WEISS, Deputy Director (A)

Institutions and Camps Branch

DAVID CROSSON, Deputy Director

Education Services Branch

MILTON BRASWELL, Deputy Director (A)

Parole Services and Community Corrections Branch

SHARON TAYLOR, Deputy Director

Administrative Services Branch
- The Worth of the Individual

We treat all people with dignity, respect, and consideration.

- People's Ability to Grow and Change

We believe people have the ability to grow and change, and we provide the opportunity for them to do so.

- Staff as our Greatest Resource

We encourage staff to develop personally and professionally and to participate in decision making.

- Ethical and Moral Behavior

We demonstrate behavior which is fair, honest, and ethical both on and off the job.

- Citizen Participation

We invite public involvement, support, and assistance to plan, deliver, and evaluate programs.

- Excellence

Our performance demonstrates a commitment to and recognition of quality, dedication, and innovation.

- A Safe and Healthy Environment

We believe that physical and mental health are important, and our commitment is to provide a safe and secure work and living environment.

This document is a research report submitted to the U.S. Department of Justice. This report has not been published by the Department. Opinions or points of view expressed are those of the author(s) and do not necessarily reflect the official position or policies of the U.S. Department of Justice. 


\title{
Identifying Mental Health Treatment Needs Among Serious Institutionalized Delinquents Using Paper-and-Pencil Screening Instruments
}

\author{
Final Report to
}

The National Institute of Justice

\section{Principal Investigators:}

\author{
Rudy Haapanen, Ph.D. \\ Chief of Research \\ California Youth Authority \\ Hans Steiner, M.D. \\ Professor of Psychiatry \\ Division of Child Psychiatry \\ Stanford University School of Medicine
}

\section{July 2003}

Prepared under grant number 98-CE-VX-0024 from the National Institute of Justice, U. S. Department of Justice. Findings, conclusions, opinions, and recommendations presented in this report are those of the authors and not necessarily those of the U. S. Department of Justice. 
This document is a research report submitted to the U.S. Department of Justice. This report has not been published by the Department. Opinions or points of view expressed are those of the author(s) and do not necessarily reflect the official position or policies of the U.S. Department of Justice. 


\section{Acknowledgments}

This research was supported by the National Institute of Justice, grant number 98-CE-VX-0024. We are grateful to the staff at NIJ for their encouragement and support for this project.

Principal Project staff at the California Youth Authority included:

Rudy Haapanen, Ph.D., Research Division, Co-principal Investigator

Lee Britton, Ph.D., Research Division

Wes Ingram, Ph.D., Research Division

Les Widerynski, Ph.D., Southern Youth Correctional Reception Center \& Clinic

Selmer Wathney, Ph.D., Northern Youth Correctional Reception Center \& Clinic

Saeed Behshid, Ph.D., Ventura Youth Correctional Facility

Patricia Morrison, Superintendent, Northern Reception Center and Clinic

Sue Brooks, Research Division

Asvi Phuong, Graduate Student Assistant, Research Division

Jaleen Tomy, Graduate Student Assistant, Research Division

Principal Project staff at Stanford University Medical School:

Hans Steiner, M.D., Co-principal Investigator

Stephanie Hawkins, Ph.D.

Allison Redlich, Ph.D.

Melissa Silverman

Project staff at University of Pittsburgh, Department of Law and Psychiatry:

Elizabeth Cauffman, Ph.D.

In addition, valuable assistance was provided by numerous staff at CYA headquarters and each of the institutions and camps. These individuals provided access to ward records and facilitated gathering of data. Graduate student assistants from throughout California collected information at these sites. Staff at the Northern Youth Correctional Reception Center \& Clinic and Southern Youth Correctional Reception Center \& Clinic and Ventura Youth Correctional Facility, listed above, assisted with data collection and also helped frame the validation issues around assessment needs at these clinics. 
This document is a research report submitted to the U.S. Department of Justice. This report has not been published by the Department. Opinions or points of view expressed are those of the author(s) and do not necessarily reflect the official position or policies of the U.S. Department of Justice. 


\section{Table of Contents}

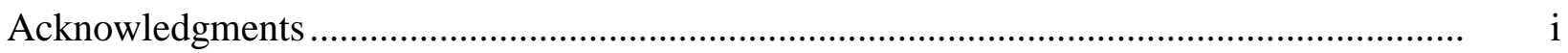

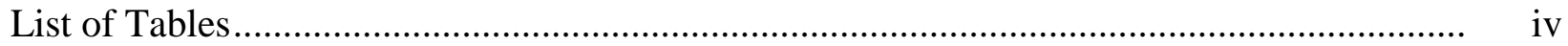

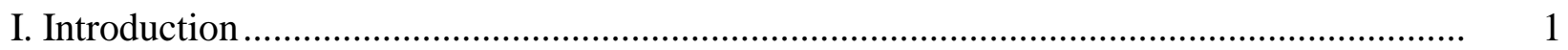

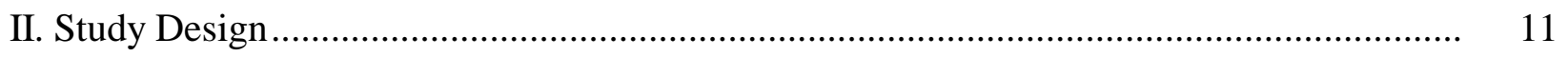

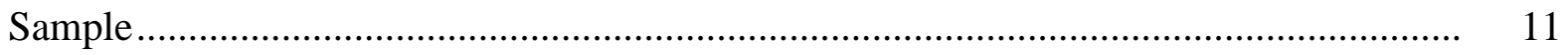

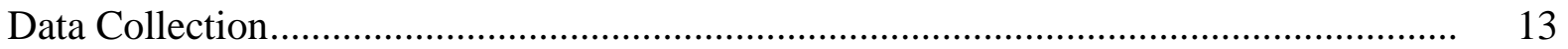

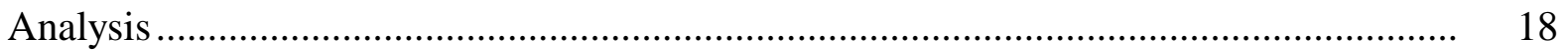

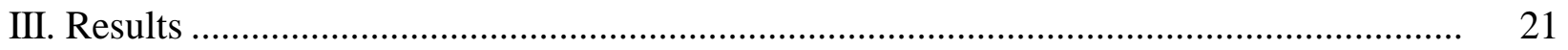

Mental Health Intervention Indicators............................................................... 21

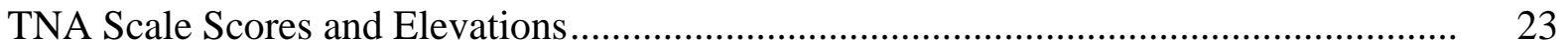

Association of TNA Scale Elevations to Intervention Indicators .................................. 25

Combinations of MAYSI Scales (Pervasiveness of Reported Mental Health Symptoms) 32

False Positive and False Negative Errors ............................................................... 35

Substance Abuse and Mental Health Comorbidity ................................................... 37

Prior Criminal Behavior ................................................................................. 39

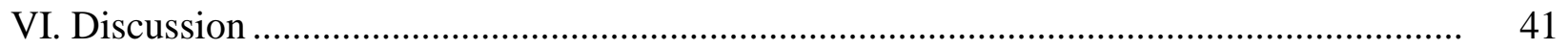

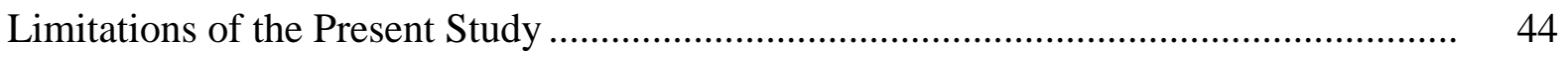

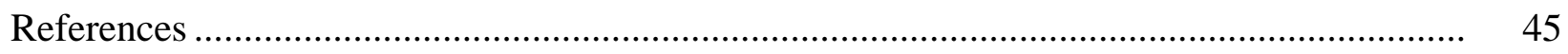

Appendix A: Instruments Included in the Study ......................................................... 49

Appendix B: Medications Indicating Mental Health Intervention ...................................... 53 


\section{List of Tables}

Table 1: Sample Demographic Characteristics and Commitment Offenses by Gender...... 12

Table 2: $\quad$ Prior Arrest Charges by Gender ............................................................. 14

Table 3: Mental Health Intervention Indicators by Gender .......................................... 22

Table 4: Massachusetts Youth Screening Instrument (MAYSI)

Scale Score Elevations by Gender.................................................................... 24

Table 5: Mean Achenbach Youth Self Report (YSR) Raw Scale Scores

and T-score Elevations By Gender................................................................... 26

Table 6: Percent with Mental Health Intervention Indicators

By MAYSI Score Elevations and Gender ........................................................ 28

Table 7: Percent with Mental Health Intervention Indicators

By YSR Score Elevations and Gender

Table 8: Percent with Mental Health Intervention Indicators

By Number of Treatment-relevant MAYSI Elevations and Gender

Table 9: Percent with Mental Health Intervention Indicators

Correctly Identified by Treatment-relevant MAYSI Elevations by Gender

Table 10: Percent with Mental Health Intervention Indicators

By DEQ and MAYSI Treatment-relevant Elevations and Gender. 


\section{Introduction}

In order to deal effectively with those young offenders committed to their care, agencies operating institutional programs for juvenile offenders should have a clear picture of the prevalence of mental health problems in their populations, by type, severity, and need for treatment. Because these problems often do not manifest themselves directly, many juvenile offenders with mental health problems may not be identified as such, but rather as "behavior problems." With better information, agencies can begin to identify, implement, and evaluate programs and services intended to reduce mental-health-related behavior problems and to aid in rehabilitative efforts by alleviating these barriers to treatment. This study sought to determine the usefulness of several paper-and-pencil screening instruments currently in use in the United States for identifying serious juvenile offenders who require mental health services while in institutional care.

The estimated prevalence of mental and emotional problems among institutionalized delinquents is very high. The backgrounds, lifestyles and "psychosocially toxic" environments (Garbarino, 1995) of these serious offenders often include abuse, both physical and verbal, and traumatic experiences. Research has shown incarcerated juvenile populations to have a very high prevalence of mental health problems (Abt Associates, 1994; Steiner, 1997; Shelton, 1998; Ulzen \& Hamilton, 1998; Hagell, 2002; Herz and Poland, 2002). These estimates are as high as $60-$ $70 \%$ for diagnosable mental disorder, including substance abuse. A study of youth committed and detained by the Maryland Juvenile Justice System found that $24 \%$ were in need of mental health services (Shelton, 1998). Anxiety Disorders, Disruptive Behavior Disorders and Substance Abuse Disorders were most frequently classified. The study also estimated that $53 \%$ of the youth had a diagnosable mental disorder. Carrion and Steiner (2000) reported very high rates of 
Dissociative Disorder in juveniles on probation. A recent study of the population at one of the CYA institutions for younger offenders found that over $30 \%$ of males and $60 \%$ of females suffered classic symptoms of Post-Traumatic Stress Disorder (PTSD) (Steiner, Garcia, and Matthews, 1997; Cauffman, Feldman, Waterman \& Steiner, 1998).

The alarmingly high rate of mental health problems in incarcerated juvenile populations suggests the need to get a clearer picture of both the prevalence of various disorders and their implications for programming. These underlying problems may be difficult to detect, but can have profound effects on functioning in institutional environments (Hagell, 2002; Herz and Poland, 2002; Steiner, Garcia, and Matthews, 1997). Wards with mental health problems tend to be needy, dangerous, and disruptive, taxing the ability of security staff and treatment program staff to provide safe, secure rehabilitative programming. Better information would help in planning the best mix of programs and programmatic approaches for the juvenile offender population: the development of programs focused directly on mental health problems and the adjustment of other programs to take into account the mental health of the participants.

While the existing research suggests at best a weak direct causal link between mental disorder and dangerousness (Mulvey, 1994), some studies of adults have found an association between certain forms of mental illness and violence (Eronen, Angermeyer, and Schulze, 1996; Steiner, Williams, Benton-Hardy, Kohler, and Duxbury, 1997). Studies of CYA wards have found certain forms of mental illness (PTSD) to be associated with lowered levels of self-restraint (Steiner, Cauffman, and Duxbury, 1999; Tinklenberg, Steiner, Huckaby, and Tinklenberg, 1996). Lowered self-restraint, in turn, has been linked to criminal outcomes both theoretically (Gottfredson and Hirschi, 1990) and empirically (Steiner, Cauffman, and Duxbury, 1999; Tinklenberg Steiner, Huckaby, and Tinklenberg, 1996). 
The vast majority of CYA wards continue to commit crimes after release and get arrested well into adulthood. Most, if not all, continue to lead difficult lives. They have unstable relationships, poor employment histories, and continued substance abuse problems (Haapanen, 1990). These latter problems predominantly affect the offenders and their families, as criminal behavior declines sharply in quantity and quality after 30 years of age (Bartol \& Bartol, 1989; Haapanen, 1990; Blumstein, Cohen, Roth, and Visher, 1986; Gottfredson and Hirschi, 1990). It is not clear at this point how the experiences of these offenders with the juvenile and criminal justice systems or treatment of any coincident mental illnesses may have affected these outcomes. However, the data suggest that psychopathology may well influence criminal (and lifestyle) outcomes for young offenders, perhaps through their effect on the impulse-control system, and it is possible that mental health treatment could have a positive effect. As costeffective treatments come to be tested and found to be effective in psychology and psychiatry (Schoenwald and Hoagwood, 2001; Burns, Hoagwood, and Mrazek, 1999), these treatments should be incorporated as major components of rehabilitation programming for juvenile offenders (Hagell, 2002; Herz and Poland, 2002).

In California, the prevalence of mental health problems among juvenile offenders is not clear. The Juvenile Justice System is a two-tier system, with the vast majority of juvenile offenders handled at the local (county) level. Each of the state's 58 counties operates its own probation department, including juvenile probation and juvenile court services. Counties have the responsibility of making services available for juvenile offenders and have a number of out-ofhome placement options available to them, including juvenile halls (for short term confinement), county-operated camps (generally up to about six months of confinement), group homes, foster homes, and privately operated residential programs. There is a clear expectation that juveniles 
will be handled at the local level until all local options have been exhausted. In practice, juveniles are handled locally unless their crimes are very serious (and long-term confinement is warranted) or they have failed a number of attempts to provide services and/or find suitable placements. There has been no systematic attempt to estimate the prevalence of mental health problems among juvenile offenders across all 58 counties.

There have also been no reliable estimates of the prevalence of mental health problems in the California Youth Authority (CYA) population. This is a very select population: commitment to the CYA is expected to be limited to juveniles who commit very serious crimes, who have extensive criminal histories, and/or who have failed at local interventions (often multiple times). In recent years, California has attempted to increasingly reserve state juvenile institutional beds for the most recalcitrant, serious, and violent juvenile offenders. Through combinations of incentives and fees, counties have been encouraged to expand local options for juvenile offenders and reduce state-level commitments.

Treatment needs often enter into these decisions as well, however. CYA commitment is a viable placement option for juveniles who require a combination of treatment and control that cannot be provided locally. County-level options for treating offenders with mental health problems, substance abuse, and sex offenses are often limited, especially in the less urban counties. Despite current efforts to expand local services, there are few placement options at the local level for juveniles with a combination of mental health problems, substance abuse and serious criminal tendencies. ${ }^{1}$ It is not surprising, therefore, that young offenders committed to

\footnotetext{
${ }^{1}$ Schools and community agencies are typically not equipped to accurately identify or act on the mental and emotional problems of these young people. Oftentimes it is only when they come to the attention of the juvenile justice system through criminal behavior that their mental and emotional problems come to be recognized. Given the commonly assumed link between mental health problems and anti-social behavior (Steadman and Cocozza, 1978), it is not surprising that the prevalence of these problems would be substantial among those in secure confinement settings.
} 
the CYA have a high prevalence of these problems in addition to their criminal behavior. Estimates of the prevalence of substance abuse problems among incoming wards, based on interviews and screening tools, are in the $70 \%$ to $80 \%$ range. It is also estimated that over $30 \%$ of wards entering the CYA will require mental health intervention during their stay. Precise estimates of need are not available, however, because the CYA has not obtained standardized diagnostic or mental health assessment information on all wards.

When juvenile offenders are committed to the CYA, they undergo a number of medical and social evaluations. Mental health screening first occurs as part of the initial "intake" evaluation at the reception centers. This screening involves reviews of case file materials, broad-ranging interviews with wards by medical personnel and their assigned clinic caseworkers, and observation by living unit staff. Wards with documented histories of mental disorder, indications of suicide threats or behaviors, bizarre or particularly aggressive criminal histories, histories of sex offending, or observed indications of serious psychological/emotional problems are referred to clinic psychologists for individual evaluation. Wards not identified or evaluated at the reception centers may be referred for psychological evaluation later on by institution staff at program institutions.

Wards found to require mental health services may be referred to Intensive Treatment Programs (ITPs), for the seriously disturbed and suicidal wards, and Specialized Counseling Programs (SCPs), for the less seriously disturbed wards. The CYA currently maintains 519 specialized mental health beds for male wards, including 140 Sex Offender Program beds, and 94 beds for females. These programs differ in staffing and in the type of intervention. Wards whose behavior suggests a danger to self or an inability to function in the institutional environment are evaluated for placement in one of the ITP or SCP programs. Once these wards are stabilized they 
may be moved down from ITP programs to the less-intensive SCP programs or from SCPs to General Population units. Once in the general population, they continue to be observed by living unit staff and may be referred for re-evaluation. Many wards move among these treatment levels a number of times during their CYA stay. Others may be referred only once for treatment and subsequently function well in their General Population units. A few remain in mental health units for their entire CYA stay.

Wards whose problems are not so serious that they require immediate intervention are maintained in General Population living units. Some are evaluated by psychologists assigned to the general population or by consulting psychologists or psychiatrists. Some are involved in individual or group counseling conducted by these mental health staff. Wards inside and outside treatment programs may also be evaluated by psychiatrists and placed on various medications.

In order to fully identify the mental health treatment needs of CYA wards, it would be helpful to have full psychological evaluations performed on each incoming ward. However, current resources allow for only a small percentage of wards to receive full psychological evaluations during the clinic process. Resources in program institutions are also limited, and it is possible that wards who could benefit from mental health treatment may be missed. Further, because these processes serve primarily as screening procedures for admission to existing mental health programs, they are undoubtedly limited somewhat by the capacity of these programs and can be expected to understate the number who experience mental health problems.

In 1996, the CYA initiated an effort to identify (or develop) a brief assessment package that would include a mental health/personality component and a substance abuse component. The goal was to implement a process by which standardized mental health and substance abuse screening information could be gathered routinely on all wards entering CYA institutions. This 
information would be used as a "back-up" to existing screening procedures and as a method of obtaining population-level estimates of mental health and substance abuse treatment needs for planning purposes.

Youth Authority clinical and research staff, with the assistance of researchers from Stanford University Medical School, developed and field-tested a mental health screening/assessment procedure that drew on extant, standardized, automated assessment tools. Instrument selection was based on the following criteria: capacity (or adaptability) for machine scoring, fourth-grade to fifth-grade reading level, gender and cultural neutrality, and suitability for group administration. The instruments also had to be brief, so that they could be incorporated into the existing clinic diagnostic process. The battery includes four instruments:

- Achenbach Child Behavior Checklist--Youth Self Report (YSR) (Achenbach, 1991);

- Massachusetts Youth Screening Instrument: Second Version (MAYSI-2) (Grisso and Barnum, 2000; Grisso, Barnum, Fletcher, Cauffman, and Peuschold, 2001);

- Weinberger Adjustment Inventory (Weinberger and Schwartz, 1990; Weinberger, 1997), which is not considered in this study ${ }^{2}$;

- Drug Experience Questionnaire (DEQ), which was designed by the author specifically for use by the CYA-it is a shortened version of the Personal Experience Inventory (Winters and Henley, 1989).

\footnotetext{
${ }^{2}$ This instrument focuses on certain self-reported areas of emotional distress, but is used by the CYA as a potential predictor of misbehavior. Research at one CYA institution indicates that the WAI can be predictive of institutional adjustment and future recidivism (Tinklenberg, Steiner, Huckaby, and Tinklenberg, 1996). Because this instrument does not focus specifically on mental health problems, however, results are not included in this report.
} 
The YSR, WAI, and DEQ were chosen to provide a broad look at the wards' thoughts, feelings, and experiences. The YSR is a well-known and widely used instrument that was believed to be able to serve as a national benchmark for understanding the CYA population. The WAI was chosen to provide information that could help understand and predict institutional behavior and subsequent adjustment on parole. The DEQ was selected based on previous satisfactory experience with the longer version-the Personal Experience Inventory-at the CYA's substance abuse treatment program institution. The shortened version dropped the psychological questions, which were considered unnecessary when the other instruments were included. The DEQ focuses only on substance abuse patterns. At that time, the MAYSI was being developed for precisely the kind of screening purposes of interest. It was included to determine whether this shorter (and less expensive) instrument could provide as useful information as the YSR. Brief descriptions of the instruments are included as Appendix A.

The assessment of all incoming wards began during the Spring of 1997 at all three reception center/clinics operated by the Youth Authority (two for males and one for females). This assessment process is formally termed the Mental Health and Substance Abuse Treatment Needs Assessment procedure, or Treatment Needs Assessment (TNA). ${ }^{3}$ Questionnaires are administered during the educational testing phase of the clinic process with 8-15 wards at a time by casework staff at the reception centers. They are then machine scored, using optical mark reader (Scantron) technology and a tailor-made scoring program. The scoring program produces a hard-copy printout, which is forwarded to casework staff for review.

\footnotetext{
${ }^{3}$ For a full description of the process and preliminary results for the CYA population, see Haapanen (2000).
} 
This assessment was not intended to replace other long-standing clinic processes, described above, to identify wards in need of immediate intervention or full psychological evaluation. Rather, it was intended primarily to inform casework decisions on wards who would otherwise not come to the attention of mental health staff. Caseworkers are expected to incorporate this information into their reports and recommendations. Because the extent of under-identification through existing processes was unknown, however, it was believed that some wards may be identified through this process for full psychological evaluations. Accordingly, if a ward scores in the elevated range on certain scales indicating possible suicidal tendencies, violence potential, or thought disturbance, a copy is forwarded to a designated psychologist. These wards are briefly interviewed as soon as possible to determine whether the scores reflect problems that require immediate attention or evaluation. If such a problem is noted, the psychologist reviews the ward's files to determine if the problem had already been identified and if the ward has already been scheduled for an evaluation. In only a few instances (and none in the sample used in this study) has this process resulted in an evaluation that was not already recommended based on earlier, more direct criteria (medical interview, file review, etc.). In these few instances, the wards were willing to admit on a questionnaire certain feelings and behaviors that they were unwilling to discuss with staff during earlier face-to-face interviews. The TNA will continue to supplement regular clinic processes by providing standardized information on all wards and by providing another source of information on wards' thoughts and feelings. Once fully validated and refined (if needed) it may also inform programming decisions for wards after they move from the reception centers to program institutions.

The value of the TNA instruments for profiling the CYA population, for gauging current mental health issues for non-clinical populations, and for helping to identify wards for whom 
psychological evaluations should be performed depends on their ability to reflect mental health treatment needs. Ideally, these instruments should be evaluated in terms of their relationship to direct indicators of mental health problems, such as diagnostic information based on DSM-IV criteria (American Psychiatric Association, 1994). ${ }^{4}$ However, as noted above, the CYA does not routinely gather diagnostic information on all incoming wards. As an alternative, it was decided to use a more limited measure: CYA mental health intervention. The present study focused on the ability of the instruments in the battery administered at reception to identify wards whose mental health problems rose to the level that services were considered appropriate during the next twelve to eighteen months. This definition, which is operationally defined in the next section, included wards who were placed in mental health programs, wards who were provided medications used to treat mental health problems, and/or wards who were identified by staff as needing mental health services, but who have not yet received them. This definition is not perfect, because some wards are placed in programs simply for evaluation or for reasons other than traditional mental health problems (e.g., violent offenders) and some wards with mental health problems may not be treated in one of these ways (e.g., mentally ill sex offenders who are treated in sex offender programs). These known limitations, described in more detail below, reduce the correspondence between mental health treatment need and these indicators. However, this criterion should still provide a rough indication of mental health treatment needs in relation to which the results of the TNA assessment can be evaluated.

\footnotetext{
${ }^{4}$ It has been argued that even these standardized criteria are inadequate because of their focus on mental disorders. A recent study of juvenile offenders in England, for example, broadened its definition of mental health problems to include "a level of symptoms of mental ill health that have led to impairment in day-to-day life" (Hagell, 2002).
} 


\section{Study Design}

This project analyzed the relationships between TNA results and mental health intervention services for a large cohort of wards entering the CYA. The data on mental health treatment was used to determine whether the TNA instruments provided an early "hint" of these treatment needs. In addition, hard-copy master files were reviewed to obtain criminal history information. These data were used to analyze the relationships between criminal behavior, TNA scores, and indicators of mental health treatment need (e.g., the mental health characteristics of violent vs. property offenders).

\section{$\underline{\text { Sample }}$}

The sample was an "intake" sample, consisting of two cohorts of wards, male and female, committed to the CYA. The sampling criteria were intended to provide an unbiased sample of commitments. The criteria differed (in terms of time frames) for the males and females because there were relatively few females committed to the CYA. In order to obtain a sample of females large enough for statistical analysis, their sampling frame was extended. The two cohorts were:

1. Males entering over a 5-month period from October 1998 through February $1999(\mathrm{n}=795)$.

2. Females entering over a 21-month period from October 1997 through June $1999(n=183)$.

An additional 34 wards entered the CYA during these periods (23 males and 11 females) for whom necessary file information was not available, mostly due to early discharges or transfer to adult corrections. These wards were dropped from the analysis. TNA data were not obtained for $142(14.5 \%)$ of the wards, due to scheduling problems at the clinics. Because the TNA was not used for formal evaluation, no attempt was made to make up these "missed" TNA assessments. In all, valid TNA data were obtained from 836 wards: 664 males (84\%) and 172 females (94\%). 
Characteristics of the sample are shown in Tables 1 and 2. Table 1 shows the Ethnicity, Age, and Commitment Offenses of the wards in these cohorts of admissions. The percentage that were male $(79.4 \%)$ is considerably lower than is typical for particular years (around 95\% males) due to the over-sampling of female wards. Other characteristics are similar in proportions to all wards entering during the year 1998 and 1999. Native American, Filipinos, Pacific Islanders, and Others each made up less than $2 \%$ of the sample; these groups were combined in the analysis reported later. Over half of the sample was committed for a violent offense, with the bulk of these being committed for Robbery or Assault. Percentages were very similar for males and females, although females had slightly higher percentages committed for Homicide. Commitments for Property Offenses, mostly Burglary, comprised $28.9 \%$ of the sample. There were fewer Burglary commitments among the females. Together, commitments for Robbery, Assault, and Burglary made up almost two-thirds $(62.5 \%)$ of the sample.

Table 2 shows the prior arrests for this sample, excluding those cases whose probation files were unavailable. These figures underscore the observation that these are very serious, chronic young offenders. Males in the sample averaged over nine prior arrest charges each, including three charges for violent offenses. Females had somewhat fewer priors (6.8), but these young women also had over two prior violent arrest charges each, on average. Only $5 \%$ of the males had as few as two prior arrest charges. A substantial proportion of these wards had 15 or more arrest charges. Among the females, almost one-fourth had one or two charges, but a considerable number $(8.5 \%)$ had fifteen or more charges. Nearly nine in ten of the males $(88.6 \%)$ and eight in ten of the females $(80.4 \%)$ had at least one violent offense. Clearly, these young men and women had substantial histories of violent and dangerous behavior. 
Table 1

Sample Demographic Characteristics and Commitment Offenses by Gender

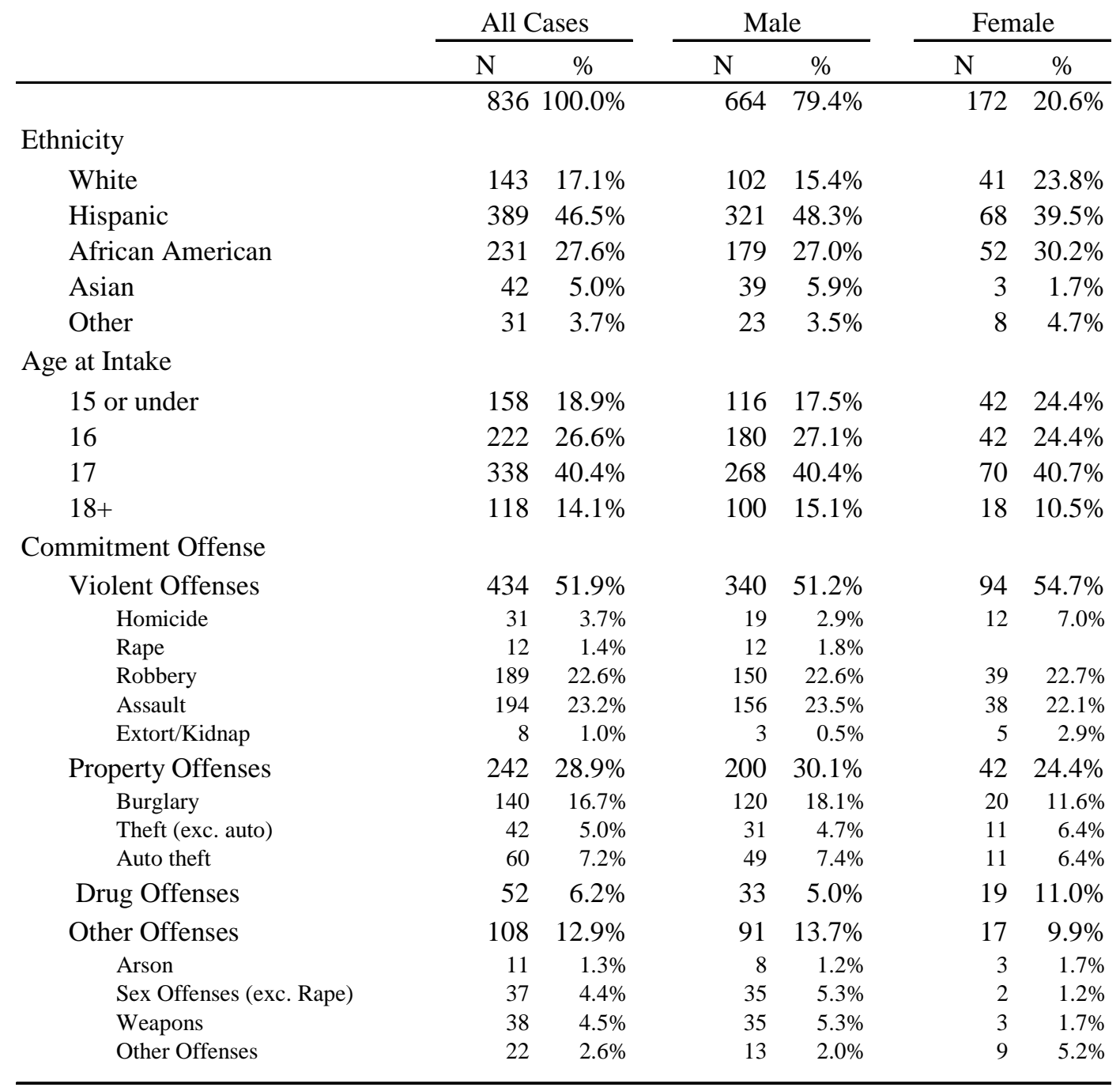

\section{$\underline{\text { Data Collection }}$}

Follow-up data focused on whether or not members of the sample:

1. Were provided mental health treatment while in CYA institutions;

2. Were prescribed medications used to treat serious mental health problems; or

3. Were identified as needing treatment by CYA treatment or clinical staff but treatment was not yet provided. 
Table 2

Prior Arrest Charges by Gender

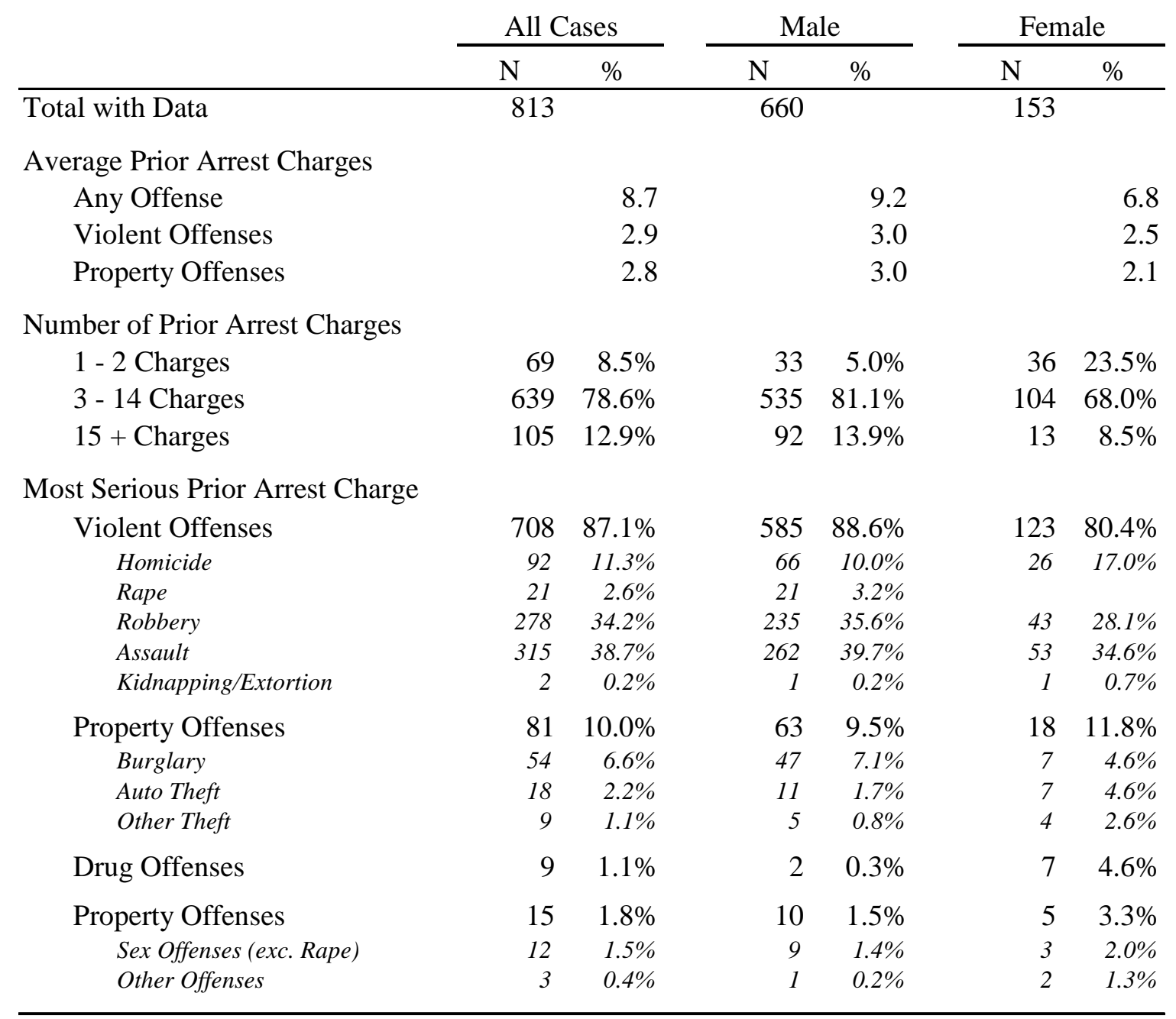

Information on mental health evaluations, treatment and medications were obtained primarily from hard-copy files maintained at ward institutions ("Field Files") and in central office ("Master Files"). ${ }^{5}$ These files were reviewed between August 1999 and the summer of 2000. Automated

\footnotetext{
5 The CYA automated data system, which was developed in the 1970s, was designed primarily to track current locations and legal requirements for wards (date of parole consideration, committing offense, etc.). It contains demographic information and decision-relevant information, but does not contain information on wards' involvement in programs, psychological evaluations, medications or staff observations of ward treatment needs. It was necessary, therefore, to obtain most information from hard-copy files.
} 
data on ward living-unit movements were collected in July, 2000 to identify any movements of sample members into living units designated as mental health treatment units. Finally, research staff reviewed central office Master Files to obtain information on criminal histories and to provide a double-check on the information obtained from Field Files.

Mental health treatment was indicated by placement on a mental health treatment unit: Intensive Treatment Programs (ITPs) or Specialized Counseling Programs (SCPs). Other types of psychological services (for example, services provided by psychologists on General Population units were not used as an indicator because the receipt of these services could not be accurately ascertained. In addition, contacts with general population psychologists may involve simple counseling or evaluation, which are less indicative of a serious mental health problem. It is possible, however, that some wards with relatively serious problems may have been treated by general population psychologists, due to lack of space on the ITP or SCP units. The present criterion (actual placement on these units) may understate the actual prevalence of mental health intervention in the sample.

Conversely, some wards placed on these units may not have had serious mental health intervention needs and may not have received mental health services. Wards whose behavior suggests possible serious psychological problems may be referred to mental health programs for evaluation and assessment of amenability for these services. Some of these wards are determined not to have mental health intervention needs and/or are considered unsuitable for these treatmentoriented programs because of their violent behavior. Information on the results of this winnowing process was often unavailable.

In addition, there are at least three types of wards who are placed on these units and who do not have classic mental health intervention needs. 
1. Sex offenders. All known sex offenders are screened for sex offender treatment. Some of these meet legal criteria for later consideration as "sexual predators' (repeat violent sex offenders) and are given highest priority for sex offender treatment. Others are evaluated in terms of risk and amenability for treatment and are placed on a priority list. Since sex offender program space is limited, wards may be placed in mental health units in lieu of sex offender program placement or until space becomes available. These wards may or may not have other psychological or mental health treatment needs.

2. Violent/aggressive wards. Wards who are extremely violent or aggressive toward staff or other wards may be referred to the mental health units for evaluation to determine if the behavior is due to a mental or psychological disturbance that can be treated in this setting. For a certain number of wards, no such disturbance is evident and they are moved to other secure settings where their behavior can be controlled.

3. Youthful Offender Parole Board Referrals. Wards may be referred for treatment or mental health screening by the Youthful Offender Parole Board because of a particularly bizarre or gruesome committing offense. Some of these wards are not deemed to be psychologically disturbed and are moved to General Population units for regular programming.

It was not possible to determine which of these wards actually did have mental health intervention needs. It was therefore assumed that all wards who were placed on mental health units had mental health intervention needs.

Prescription of psychotropic medications was indicated by notation in the medical file that the ward had been prescribed medications commonly used in the treatment of psychological 
disorders. Medications that met this criterion are listed by their common uses in Appendix B. Due to difficulty in interpreting notations in medical files, no attempt was made to code or analyze the reasons for prescribing these medications, their dosages, their durations, or the wards' responses to them. The variable was dichotomized as medication/ no medication.

Other indicators of the need for mental health services included

- placement on a "waiting list" for mental health programs,

- $\quad$ suicide-risk evaluation in the moderate or high range, or

- observation by living unit staff, teachers or caseworkers.

The last category was used to identify wards whose behavior had not called for intervention, but who were felt to be in need of services. Staff working with these wards were asked to indicate whether, at the time of the data collection, wards in the sample needed ITP or SCP services. All but a few of the wards who were identified in this way also had other indicators of mental health intervention or were currently being treated. Research staff reviewed the files of those that did not have other indicators to verify that these wards were experiencing mental health-related problems. Only three wards were verified in this way. These wards were noted to be experiencing mental health difficulties and were awaiting evaluation by psychologists. The other ("non-verified") wards were sex offenders or wards with behavioral problems that staff believed should be evaluated by mental health staff but who were not experiencing mental health symptoms. ${ }^{6}$

\footnotetext{
${ }^{6}$ In itself, this discovery of only a small number of "hidden" wards with possible serious mental health problems is a positive finding. It attests to the success of CYA staff at identifying these wards and getting them evaluated for treatment.
} 


\section{$\underline{\text { Analysis }}$}

Analyses focused primarily on the usefulness of the assessment data for identifying wards who received the mental health interventions discussed above. Elevated scores on the Massachusetts Youth Screening Instrument (MAYSI), the Achenbach Child Behavior Checklist-Youth Self-Report (YSR), and the Drug Experience Questionnaire (DEQ) were based on cut-scores provided by the authors. The proportions of those with indicators of mental health intervention need were compared for wards with "normal" and "elevated" scores on each scale.

For the MAYSI analyses, all scales were used, including Traumatic Experiences, Thought Disturbance for females, and a simple index of Seeing/Hearing Things, described below. Wards scoring at the "warning" level were considered to have "elevated" scores. The authors do not recommend using the Traumatic Experiences Scale for screening purposes and did not provide a cut-off score for the this scale, which focuses on past traumatic events. It was included in order to explore its possible usefulness in this population. A cut-off score for this scale was developed for CYA use by Elizabeth Cauffman, based on her research on Posttraumatic Stress Disorder (PTSD) in the CYA population (Cauffman, Feldman, Waterman, and Steiner, 1998). The cut-score was the average scale score of wards who were positive for PTSD. For similar reasons, we chose to include the Thought Disturbance results for females in this study, even though the author did not identify this scale in his factor analysis of the development sample. Our earlier experience with the first version of MAYSI scales, along with exploratory factor analysis on the full CYA population, suggested that this scale was as useful for females as for males. In this study, we used the cut-off score provided by the author for males. 
In addition to the MAYSI Thought Disturbance scale, a two-tem index of "Seeing/Hearing Things" was constructed. Wards were considered to have elevated scores if they answered "Yes" to either of these questions:

Have you seen things that other people say are not really there?

Have you heard voices other people can't hear?

These experiences were felt by psychologists (who consulted on this study) to be of greatest interest in identifying wards for possible treatment. Other Thought Disturbance items include:

Have other people been able to control your brain or your thoughts?

Have you had a bad feeling that things don't seem real, like you're in a dream?

Has it been hard for you to feel close to people outside your family?

These items may indicate realistic appraisals of life experience during incarceration, where staff are attempting to change wards' thought processes and where wards may be disoriented by the commitment process. Accordingly, specific indications of "hearing things" or "seeing things" was considered of greater interest for indicating the need for treatment.

The MAYSI analysis also focused on combinations of certain scales, with particular emphasis on three major dimensions that are of greatest direct relevance to identifying wards for mental health treatment in the CYA: Depressed-Anxious, Suicide Ideation, and Thought Disturbance (including Seeing/Hearing Things). These scales were analyzed in combination to establish the pervasiveness of a ward's self-reported mental health symptoms. Analysis also focused on the co-occurrence of these symptoms with self-reported substance abuse problems.

For all analyses, Chi-square tests were used to assess statistical significance of relationships. These comparisons all involved discrete groups based on existing cut-points and/or collapsing of scale scores. The intent of these analyses was to ascertain the usefulness of the individual scales 
as they were developed and as they were intended to be used, with wards classified as having elevated levels on the basis of simple rules and cut-points. The analysis did not attempt to determine the best combination of scale scores or elevations for predicting subsequent mental health intervention, nor did it attempt to determine weights to apply to scale scores to differentially assess their usefulness in relation to one another. 


\section{Results}

\section{$\underline{\text { Mental Health Intervention Indicators }}$}

The number and percent of the CYA sample that had various indicators of mental health intervention needs - types and levels of mental health intervention or identification — are shown in Table 3. In all, 319 sample members (38\%) had at least one indicator of mental health intervention during the observation period. About $18 \%$ of the sample had been placed at least once in a mental health program (ITP or SCP) and $21 \%$ had one or more prescriptions for medications typically used to treat psychological problems. Combined, $29.5 \%$ of the sample was either placed in a mental health program, were prescribed psychotropic medications, or both. Another $8.6 \%$ was identified as having mental health intervention needs on the basis of psychological evaluations, suicide referrals, or verified staff observations. Of those with any of these mental health intervention indicators, over half $(56.7 \%)$ had more than one such indicator.

These percentages differed markedly for males and females: a much larger percentage of females were placed in programs or prescribed medication or both. Nearly $46 \%$ of the females were placed at least once in a mental health program (compared to $11 \%$ of the males), and $42 \%$ of the females were prescribed psychotropic medications (compared to $16 \%$ for males). In all, over two-thirds of the female wards in the sample had at least one indicator of mental health intervention, (compared to $31 \%$ of the males) and two-thirds of the females with any indicators had multiple indicators (compared to about half of the males who had any indicators). These differences may be due, in part, to the greater availability of services for female wards, but that availability was due to a greater perceived need for these services for females. Clinical staff who 
Table 3

Mental Health Intervention Indicators

By Gender

\begin{tabular}{|c|c|c|c|c|c|c|}
\hline & \multicolumn{2}{|c|}{ All Cases } & \multicolumn{2}{|c|}{ Male } & \multicolumn{2}{|c|}{ Female } \\
\hline & $\mathrm{N}$ & $\%$ & $\mathrm{~N}$ & $\%$ & $\mathrm{~N}$ & $\%$ \\
\hline Cases in Sample & 836 & & 664 & & 172 & \\
\hline Any Major Validation Indicator & 319 & $38.2 \%$ & 205 & $30.9 \%$ & 114 & $66.3 \%$ \\
\hline \multicolumn{7}{|l|}{ Type of Validation Indicator } \\
\hline Mental Health Program & 152 & $18.2 \%$ & 73 & $11.0 \%$ & 79 & $45.9 \%$ \\
\hline Psychotropic Rx & 177 & $21.2 \%$ & 105 & $15.8 \%$ & 72 & $41.9 \%$ \\
\hline Mental Health Program or Rx & 247 & $29.5 \%$ & 141 & $21.2 \%$ & 106 & $61.6 \%$ \\
\hline Other Indicator & 72 & $8.6 \%$ & 64 & $9.6 \%$ & 8 & $4.7 \%$ \\
\hline \multicolumn{7}{|c|}{ Number of Validation Indicators (if any) } \\
\hline Single & 138 & $43.3 \%$ & 101 & $49.3 \%$ & 37 & $32.5 \%$ \\
\hline Multiple & 181 & $56.7 \%$ & 104 & $50.7 \%$ & 77 & $67.5 \%$ \\
\hline
\end{tabular}

work with female wards have long argued that there is a much higher prevalence of mental health problems among females committed to CYA institutions.

It should be noted that of the wards with at least one indicator, the vast majority were identified as needing mental health services or evaluation during the intake clinic process (not shown in the tables). Virtually all wards who were admitted to ITP or SCP programs were identified at the clinics. Wards whose only interventions were psychotropic medications or referrals for suicidal tendencies were more likely to have been identified later during their stays. The figures suggests that current clinical practices successfully identify the vast majority of those wards who require intensive interventions during their CYA stays. 


\section{TNA Scale Scores and Elevations}

Percentages with elevated scores on the Massachusetts Youth Screening Instrument (MAYSI) are displayed in Table 4. The first three columns of this table show, by gender, the percentage of wards who scored above the "Caution" cut-off for each scale. The remaining three columns show the percentage who scored above the "Warning" cut-off. Percentages above the "Caution" level ranged from $21.9 \%$ (Suicide Ideation) to $58.5 \%$ (Thought Disturbance) in this sample. Percentages at or above the "Warning" level ranged between $11.4 \%$ (Suicide Ideation) to $26.3 \%$ (Thought Disturbance). These percentages are very similar to percentages for all 6,500 wards who have completed the assessment since it was implemented in April, 1997.

The percentage of males scoring at the "Caution" or "Warning" levels differed from that of females only on a few scales. More males scored at the Caution level than females on Alcohol/Drug Use and Somatic Complaints. More females had scores at this level on the Depressed/Anxious Scale. At the "Warning" level, males and females did not differ in their percentages except for the Depressed/Anxious scale, where more females had elevated scores. Four of five of these wards reported experiencing or witnessing violent or traumatic events in their pasts. Half of the females in the sample and four in ten of the males responded "yes" to four out of five of these questions (see footnote 7 , page 28 , for a list of these items).

These percentages are higher than those reported for other juvenile justice samples of detainees in Texas (Schwank, Espinosa, and Tolbert, 2003) and Maryland (Maryland Department of Juvenile Justice, 2001). Both of these states reported $20 \%$ to $30 \%$ of their juvenile detainees scoring in the Caution range or above, compared to $40 \%$ to $50 \%$ for most of the scales in the CYA sample. Results similar to this sample were found in Pennsylvania detention centers (Griffin, 2000). This growing body of data from around the nation tend to confirm the belief that young 
Table 4

Massachusetts Youth Screening Instrument (MAYSI)

Scale Score Elevations by Gender

\begin{tabular}{|c|c|c|c|c|c|c|}
\hline & \multicolumn{3}{|c|}{$\begin{array}{c}\text { "Caution" or "Warning" } \\
\text { Elevations }\end{array}$} & \multicolumn{3}{|c|}{ "Warning" Elevations } \\
\hline & $\begin{array}{c}\text { All } \\
\text { Cases }\end{array}$ & Male & Female & $\begin{array}{c}\text { All } \\
\text { Cases }\end{array}$ & Male & Female \\
\hline $\mathrm{N}$ of cases & 835 & 663 & 172 & 835 & 663 & 172 \\
\hline Alcohol/Drug Use & $51.8 \%$ & $55.2 \%$ & $39.0 \% * *$ & $20.1 \%$ & $22.3 \%$ & $11.6 \% * *$ \\
\hline Angry/Irritable & $39.4 \%$ & $38.5 \%$ & $43.0 \%$ & $11.9 \%$ & $11.1 \%$ & $15.1 \%$ \\
\hline Depressed/Anxious & $44.9 \%$ & $43.0 \%$ & $52.3 \% *$ & $12.0 \%$ & $9.7 \%$ & $20.9 \% * *$ \\
\hline Somatic Complaints & $47.1 \%$ & $47.9 \%$ & $44.2 \% *$ & $14.8 \%$ & $15.0 \%$ & $14.0 \%$ \\
\hline Suicide Ideation & $21.9 \%$ & $20.4 \%$ & $27.9 \%$ & $11.4 \%$ & $10.4 \%$ & $15.1 \%$ \\
\hline Thought Disturbance & $58.5 \%$ & $58.9 \%$ & $57.0 \%$ & $26.3 \%$ & $26.3 \%$ & $26.2 \%$ \\
\hline Traumatic Experiences & $81.4 \%$ & $82.5 \%$ & $77.3 \%$ & $44.3 \%$ & $42.7 \%$ & $50.6 \% *$ \\
\hline
\end{tabular}

* Chi-square $\mathrm{p}<.05$

** Chi-square $\mathrm{p}<.01$

offenders committed to the CYA have a relatively high rate of self-reported mental health problems. Reasons for the differences in results found in different jurisdictions, however, are not clear due to differences in local juvenile justice systems and detention practices.

Further, a number of studies report much higher rates of elevated scores for females than males (Stewart and Trupin, 2003; Griffin, 2000). These large differences were not found in this sample. Although the reasons for these differences are not known, it is possible that young women with mental health issues are more likely to be found at earlier points of detention, such as juvenile halls, than in state-level institutional placements. Most other states reported findings for initial detention, which occurs at the county level in California.

The Achenbach Child Behavior Checklist-Youth Self-Report (YSR) was included in the TNA battery because its widespread use, particularly in California, would set the stage for ongoing 
comparison of YA wards to other juvenile populations. YSR cut-off scores were selected by the authors to identify the top $2 \%$ of subjects (corresponding to a T-score of 70 ) for individual scales and the top $10 \%$ for the summary Internalizing, Externalizing, and Total scores (T-scores above 64). As shown in Table 5, higher percentages (typically two to three times as high) were found among CYA wards, although these percentages were generally under $10 \%$. For males, these percentages ranged from 3\% for Aggressive Behavior up to 30\% for Delinquent Behavior. For females, elevated scores ranged from a low of $4 \%$ for Social Problems to a high of $34 \%$ for Delinquent Behavior. These results also point to a relatively high prevalence of mental health problems in this population, but suggest a lower level of psychopathology than do the MAYSI results.

\section{$\underline{\text { Association of TNA Scale Elevations to Intervention Indicators }}$}

As described above, the TNA was not used as part of the formal identification and evaluation process at the CYA. Although the TNA results were reviewed by psychologists and caseworkers, decisions regarding the need for full psychological evaluations and/or mental health treatment were based on traditional clinical practices. These staff reported that no treatment recommendations were based solely on TNA results. Thus, there is no built-in relationship expected between these indicators of subsequent mental health intervention and TNA scores.

The relationship between elevated scores on the Massachusetts Youth Screening Instrument (MAYSI) and mental health intervention in the CYA is displayed in Table 6. The first two columns of this table show, by gender, the number and percentage of wards who scored in the elevated range (at the "Warning" level) for each scale on the MAYSI. The remaining rows show the percent of those in each row who had indicators of subsequent mental health intervention 
Table 5

Mean Achenbach Youth Self Report (YSR) Raw Scale Scores

and T-score Elevations By Gender

\begin{tabular}{lrrrrrrrr} 
& \multicolumn{3}{c}{ Means } & & \multicolumn{3}{c}{ T-score Elevations } \\
\cline { 2 - 5 } \cline { 6 - 8 } & All & & & & All \\
& Cases & Male & Female & & Cases & Male & Female \\
\hline N of cases & 832 & 660 & 172 & & 832 & 660 & 172 \\
Withdrawn & 4.41 & 4.29 & $4.89 *$ & & $5.5 \%$ & $5.6 \%$ & $5.2 \%$ \\
Somatic Complaints & 2.54 & 2.26 & $3.60 *$ & & $4.7 \%$ & $4.7 \%$ & $4.7 \%$ \\
Anxious/Depressed & 7.90 & 7.65 & $8.86 * *$ & & $8.5 \%$ & $8.5 \%$ & $8.7 \%$ \\
Social Problems & 2.93 & 2.96 & 2.83 & & $4.9 \%$ & $5.2 \%$ & $4.1 \%$ \\
Thought Problems & 3.81 & 3.81 & 3.84 & & $11.3 \%$ & $11.8 \%$ & $9.3 \%$ \\
Attention Problems & 5.17 & 5.22 & 5.01 & & $7.3 \%$ & $8.0 \%$ & $4.7 \%$ \\
Delinquent Behavior & 7.52 & 7.62 & 7.10 & & $30.7 \%$ & $29.7 \%$ & $34.3 \%$ \\
Aggressive Behavior & 7.92 & 7.78 & 8.47 & & $4.8 \%$ & $3.2 \%$ & $11.0 \% * * * *$ \\
Internalizing & 14.09 & 13.47 & $16.49 * *$ & & $19.6 \%$ & $19.4 \%$ & $20.3 \%$ \\
Externalizing & 15.44 & 15.41 & 15.57 & & $20.7 \%$ & $18.1 \%$ & $30.8 \% * * * *$ \\
Total & 49.38 & 48.78 & 51.71 & & $23.7 \%$ & $24.0 \%$ & $22.7 \%$ \\
\hline
\end{tabular}

* Student's T p $<.05$

** Student's T p $<.01$

$* * * \quad$ Chi-square $\mathrm{p}<.05$

$* * * * \quad$ Chi-square $\mathrm{p}<.01$

needs in the CYA. The first of these columns (the third column on the table) shows the percent who had at least one ("Any") of the indicators. The remaining columns show the percent who had the two most important indicators: placement in CYA mental health program units and prescription of medications used to treat serious psychological disturbances. These last two columns are non-exclusive-wards could have been placed in a mental health unit or provided psychotropic medication or both. Other indicators, such as placement on a waiting list for mental health programs, referral for suicide intervention, or staff observations, are not shown.

For males and females, the first row displays the percentages with these indicators of mental health intervention for all wards with valid MAYSI assessments. These figures correspond to the 
figures on Table 3, except that one ward in the sample did not complete the MAYSI assessment, leaving 663 male wards in this analysis. These figures can serve as a "baseline" against which to compare the remaining figures on the table. For example there were 73 male wards who scored in the elevated range on the Angry-Irritable Scale (11\% of the sample). Of these 73 wards, $58.9 \%$ had at least one indicator of mental health intervention needs, compared to the base rate of $30.9 \%$ for the entire male sample. About 22\% (21.9\%) of these 73 wards had at least one placement in a mental health unit, and $28.8 \%$ had one or more prescriptions for medications used to treat serious mental health problems.

Each of the MAYSI scale elevations identified a different percentage of the males in the sample, and each scale, except Traumatic Experiences, was able to pick out wards who were more likely than others to be identified later as having mental health intervention needs and/or to obtain mental health services. The most accurate predictions were associated with the Suicide Ideation scale, which identified $10 \%$ of the sample. These 69 wards were most likely to have one or more of the indicators of mental health intervention $(73.9 \%)$, to have been placed on a mental health living unit (40.6\%) and to be placed on psychotropic medications (46.4\%). Wards with elevated scores on scales focusing on traditional concerns of mental health systems (Depressed-Anxious, Suicide Ideation, and Thought Disturbance-especially Seeing/Hearing Things) had the highest rates of subsequent identification and intervention.

The identification and treatment of potentially suicidal wards is of critical importance to the CYA, and it is not surprising that wards with elevated Suicide Ideation scores received attention. Only rarely does this scale identify a ward who has not already been identified in other ways. Because it relies on prior thoughts, feelings, and behaviors, however, a high score on this scale does not necessarily mean that the ward is currently suicidal. Still, the high identification/ 
Table 6

Percent with Mental Health Intervention Indicators

By MAYSI Score Elevations and Gender

\begin{tabular}{|c|c|c|c|c|c|}
\hline & \multirow[b]{2}{*}{ Cases } & \multirow[b]{2}{*}{$\begin{array}{c}\% \text { of } \\
\text { Sample }\end{array}$} & \multicolumn{3}{|c|}{ Mental Health Intervention Indicator } \\
\hline & & & Any & $\begin{array}{l}\text { Placed in } \\
\text { MH Unit }\end{array}$ & $\begin{array}{c}\text { Psychotropic } \\
\text { Rx } \\
\end{array}$ \\
\hline \multicolumn{6}{|l|}{ Male } \\
\hline All cases & 663 & & $30.9 \%$ & $11.0 \%$ & $15.8 \%$ \\
\hline Alcohol/Drug Use & 147 & $22 \%$ & $42.2 \% * *$ & $17.0 \% * *$ & $23.8 \% * *$ \\
\hline Angry/Irritable & 73 & $11 \%$ & $58.9 \% * *$ & $21.9 \% * *$ & $28.8 \% * *$ \\
\hline Depressed/Anxious & 64 & $10 \%$ & $67.2 \% * *$ & $29.7 \% * *$ & $35.9 \% * *$ \\
\hline Somatic Complaints & 99 & $15 \%$ & $54.5 \% * *$ & $21.2 \% * *$ & $32.3 \% * *$ \\
\hline Suicide Ideation & 69 & $10 \%$ & $73.9 \% * *$ & $40.6 \% * *$ & $46.4 \% * *$ \\
\hline Thought Disturbance & 174 & $26 \%$ & $45.4 \% * *$ & $20.7 \% * *$ & $28.7 \% * *$ \\
\hline Seeing/Hearing Things & 134 & $20 \%$ & $53.0 \% * *$ & $23.9 \% * *$ & $32.8 \% * *$ \\
\hline Traumatic Experiences & 281 & $42 \%$ & $36.7 \% * *$ & $13.5 \%$ & $18.1 \%$ \\
\hline \multicolumn{6}{|l|}{ Female } \\
\hline All cases & 172 & & $66.3 \%$ & $45.9 \%$ & $41.9 \%$ \\
\hline Alcohol/Drug Use & 20 & $12 \%$ & $80.0 \%$ & $65.0 \%$ & $40.0 \%$ \\
\hline Angry/Irritable & 26 & $15 \%$ & $84.6 \% *$ & $65.4 \% *$ & $46.2 \%$ \\
\hline Depressed/Anxious & 36 & $21 \%$ & $75.0 \%$ & $61.1 \% *$ & $58.3 \% *$ \\
\hline Somatic Complaints & 24 & $14 \%$ & $75.0 \%$ & $62.5 \%$ & $45.8 \%$ \\
\hline Suicide Ideation & 26 & $15 \%$ & $73.1 \%$ & $57.7 \%$ & $57.7 \%$ \\
\hline Thought Disturbance & 45 & $26 \%$ & $77.8 \%$ & $64.4 \% * *$ & $53.3 \%$ \\
\hline Seeing/Hearing Things & 28 & $16 \%$ & $85.7 \% *$ & $71.4 \% * *$ & $57.1 \%$ \\
\hline Traumatic Experiences & 87 & $51 \%$ & $69.0 \%$ & $51.7 \%$ & $47.1 \%$ \\
\hline
\end{tabular}

$* *$ Chi-square $\mathrm{p}<.01$

$*$ Chi-square $\mathrm{p}<.05$

intervention rate for these wards suggests the value of this kind of paper-and-pencil screening tool for obtaining useful information about the mental state of the wards.

For female wards, a slightly different pattern emerged. In terms of any identification by CYA staff as having mental health intervention needs, the only statistically significant improvement over the base rate prediction of $66.3 \%$ came from Seeing/Hearing Things (85.7\%) and Angry- 
Irritable (84.6\%). These are accompanied by statistically significant relationships between these scales and placement in mental health units (71.4\% and $65.4 \%$, respectively). Two other scales (Depressed-Anxious and the original Thought Disturbance, which is not supposed to be used for females) also were associated with placement in mental health programs. Other scales, including Suicide Ideation, were not were associated with these placements. Only the Depressed-Anxious scale was associated with psychotropic medications for females.

Overall, these scales did not appear to be as helpful for identifying female wards who received attention for mental health problems as they did for males. While the percentage of female wards with mental health service indicators was twice as high as for males $(66.3 \%$ vs. $30.9 \%)$, the percentage with scale elevations was not that different. Further, elevations on these scales did not differentiate as well among the female wards. Based on the clinical experience of CYA mental health staff, the differences in treatment service indicators between male and female wards more closely reflect actual differences in the prevalence of mental health problems than do differences in scale scores. It would appear that the MAYSI scales understated the extent of possible mental health problems for these female wards.

In addition to the more traditional problem scales, the Angry-Irritable scale had some value for identifying female wards who were subsequently referred to mental health programs. This relationship may reflect the greater availability of these services for female wards in the CYA, coupled with a lower availability of lock-up units at the female facility. Female wards who act out aggressively may be more likely than their male counterparts to be referred to the relativelysecure Special Counseling Program unit for evaluation, treatment and control. 
Traumatic Experiences ${ }^{7}$, both for males and for females, did not seem to be associated with subsequent mental health intervention in the CYA. None of the comparisons found a statistically significant relationship between Traumatic Experiences elevations and any of the three main mental health intervention indicators, except for the global (Any) indicator for males. A similar result was found in a study comparing actual Post-Traumatic Stress Disorder (PTSD) rates among randomly selected CYA wards to those who were referred to mental health programs. No significant differences in prevalence of PTSD were found, suggesting that staff generally did not identify wards with PTSD and did not refer wards to mental health programs solely for PTSD problems (Steiner, Cauffman, and Duxbury, 1999).

Similar information for the 660 males and 172 females with valid scores on the Achenbach CBCL-YSR are shown in Table 7. As noted earlier, the YSR cut-points identify a smaller proportion of the sample than do the MAYSI cut-points. Nevertheless, the proportion of the CYA population with elevated scores is several times greater than would be expected in a normal population. The cut-points were selected by the authors to identify about $2 \%$ of the normal population $(\mathrm{T}=70+)$ for the individual scales and about $10 \%$ of the normal population $(\mathrm{T}=64+)$ for the summary Internalizing, Externalizing, and Total scores. For males, relatively high percentages were noted for Thought Problems (12\%) and for Delinquent Behavior (30\%). Surprisingly, only $3 \%$ of these serious delinquents scored in the elevated range on the Aggressive Behavior scale.

\footnotetext{
${ }^{7}$ Elevated scores on this scale were defined as affirmative answers to at least four of five questions (one question differed for males and females): MAYSI 46. (Males Only) Have people talked about you a lot when you're not there? MAYSI 48. Have you EVER (IN YOUR WHOLE LIFE) had something very bad or terrifying happen to you? MAYSI 49. Have you EVER been badly hurt, or been in danger of getting badly hurt or killed? MAYSI 50. (Females Only) Have you EVER been raped, or been in danger of getting raped? MAYSI 51. Have you EVER had a lot of bad thoughts or dreams about a bad or scary event that happened to you? MAYSI 52. Have you EVER seen someone severely injured or killed (in person-not in movies or TV)?
}

This criteria identified $42 \%$ of the males and $51 \%$ of the females in the sample. Clearly, these wards have experienced considerable trauma in their lives. 
Table 7

Percent with Mental Health Intervention Indicators

By YSR Score Elevations and Gender

\begin{tabular}{|c|c|c|c|c|c|}
\hline & \multirow[b]{2}{*}{ Cases } & \multirow[b]{2}{*}{$\begin{array}{c}\% \text { of } \\
\text { Sample }\end{array}$} & \multicolumn{3}{|c|}{ Mental Health Intervention Indicator } \\
\hline & & & Any & $\begin{array}{l}\text { Placed in } \\
\text { MH Unit }\end{array}$ & $\begin{array}{c}\text { Psychotropic } \\
\text { Rx } \\
\end{array}$ \\
\hline \multicolumn{6}{|l|}{ Male } \\
\hline Valid Cases & 660 & & $30.8 \%$ & $11.1 \%$ & $15.6 \%$ \\
\hline Withdrawn & 37 & $6 \%$ & $59.5 \% * *$ & $21.6 \% *$ & $35.1 \% * *$ \\
\hline Somatic Complaints & 31 & $5 \%$ & $51.6 \% * *$ & $29.0 \% * *$ & $35.5 \% * *$ \\
\hline Anxious/Depressed & 56 & $8 \%$ & $48.2 \% * *$ & $25.0 \% * *$ & $28.6 \% * *$ \\
\hline Social Problems & 34 & $5 \%$ & $52.9 \% * *$ & $32.4 \% * *$ & $41.2 \% * *$ \\
\hline Thought Problems & 78 & $12 \%$ & $57.7 \% * *$ & $24.4 \% * *$ & $42.3 \% * *$ \\
\hline Attention Problems & 53 & $8 \%$ & $54.7 \% * *$ & $28.3 \% * *$ & $37.7 \% * *$ \\
\hline Delinquent Behavior & 196 & $30 \%$ & $38.8 \% * *$ & $12.8 \%$ & $21.9 \% * *$ \\
\hline Aggressive Behavior & 21 & $3 \%$ & $52.4 \% *$ & $38.1 \% * *$ & $33.3 \% *$ \\
\hline Internalizing & 129 & $20 \%$ & $47.3 \% * *$ & $23.3 \% * *$ & $27.9 \% * *$ \\
\hline Externalizing & 119 & $18 \%$ & $48.7 \% * *$ & $19.3 \% * *$ & $26.9 \% * *$ \\
\hline Total & 159 & $24 \%$ & $49.1 \% * *$ & $22.6 \% * *$ & $28.3 \% * *$ \\
\hline \multicolumn{6}{|l|}{ Female } \\
\hline Valid Cases & 172 & & $66.3 \%$ & $45.9 \%$ & $41.9 \%$ \\
\hline Withdrawn & 9 & $5 \%$ & $66.7 \%$ & $66.7 \%$ & $44.4 \%$ \\
\hline Somatic Complaints & 8 & $5 \%$ & $100.0 \% *$ & $100.0 \% * *$ & $87.5 \% * *$ \\
\hline Anxious/Depressed & 15 & $9 \%$ & $86.7 \%$ & $73.3 \% *$ & $60.0 \%$ \\
\hline Social Problems & 7 & $4 \%$ & $71.4 \%$ & $71.4 \%$ & $71.4 \%$ \\
\hline Thought Problems & 16 & $9 \%$ & $87.5 \%$ & $68.8 \%$ & $56.3 \%$ \\
\hline Attention Problems & 8 & $5 \%$ & $87.5 \%$ & $87.5 \% *$ & $75.0 \%$ \\
\hline Delinquent Behavior & 59 & $34 \%$ & $74.6 \%$ & $59.3 \% *$ & $52.5 \% *$ \\
\hline Aggressive Behavior & 19 & $11 \%$ & $100.0 \% * *$ & $89.5 \% * *$ & $73.7 \% * *$ \\
\hline Internalizing & 35 & $20 \%$ & $74.3 \%$ & $62.9 \% *$ & $54.3 \%$ \\
\hline Externalizing & 53 & $31 \%$ & $83.0 \% * *$ & $60.4 \% *$ & $58.5 \% * *$ \\
\hline Total & 39 & $23 \%$ & $89.7 \% * *$ & $71.8 \% * *$ & $61.5 \% * *$ \\
\hline
\end{tabular}

** Chi-square $\mathrm{p}<.01$

$*$ Chi-square $\mathrm{p}<.05$

All of the scales identified groups with higher rates of mental health interventions than the base rate of $30.8 \%$. The percentage of those with elevated scores on various subscales who had subsequent indicators of mental health needs ranged from $38.8 \%$ for the Delinquent Behavior 
scale to $59.5 \%$ for the Withdrawn scale. All of these relationships were statistically significant at the $\mathrm{p}<.01$ level except Aggressive Behavior, which was significant at the $\mathrm{p}<.05$ level.

The results for females were consistent with those for males. Percentages with elevated scores ranged from $5 \%$ to $9 \%$ on most scales, with Delinquent Behavior again being very prevalent (34\%). A higher percentage of females than males scored in the elevated range on Aggressive Behavior (11\% vs. 3\%). The higher Aggressive Behavior prevalence and the slightly higher prevalence of Delinquent Behavior elevations brought the percentage of females with elevated Externalizing Tendencies scores higher than for males as well.

For identifying females with any subsequent mental health problem indicators (“Any”), significant relationships were found for Somatic Complaints, Aggressive Behavior, Externalizing Tendencies and Total Score. These behavior-oriented scales were also found to be associated with placement in mental health units and prescription of psychotropic medications specifically. With the exception of the Anxious-Depressed scale, which was related to placement in mental health programs, the scales focusing on traditional mental health issues (Anxious/Depressed, Social Problems, Thought Problems, Withdrawn) were not associated with any of the indicators of mental health intervention need for females in this sample at the $\mathrm{p}<.05$ level.

\section{Combinations of MAYSI Scales (Pervasiveness of Reported Mental Health Symptoms)}

Combinations of those MAYSI scales focused on certain mental health problem areas may be able to identify wards with mental health service need indicators more effectively than single scales. A reasonable use of a mental health screening instrument of this kind would be to identify wards who scored high on any of several scales for further evaluation. Scales that seem most relevant for identifying those in need of traditional mental health services include Depressed- 
Anxious, Suicide Ideation, and Thought Problems (including Seeing/Hearing Things). As discussed earlier, however, we would not necessarily expect these relationships to be very strong. A certain amount of over-prediction is intended in order to make the instruments more "sensitive (to reduce false negative errors). In addition, because many wards are placed in treatment programs for reasons other than traditional mental health problems, we would expect attenuated relationships between these kinds of scales and these indicators of mental health intervention. Nevertheless, we should find significant relationships if the instruments are useful at all for identifying these wards.

The results of these analyses are shown in Table 8 . The results suggest that wards selfreporting symptoms in more than one of these domains were more likely to be identified later as needing mental health intervention. Among the males, those with elevations on any of these particular scales comprised $34 \%$ of the sample. Of these cases $48.2 \%$ had one or more indicator of mental health intervention needs in the CYA, compared to only $22 \%$ of those who had none of these elevations. Wards with two or more of these scale elevations comprised $10 \%$ of the males, and nearly $70 \%$ of these wards $(68.7 \%)$ were identified for mental health services later on. Wards who met these criteria (one-or-more elevations and two-or-more elevations) were twice as likely and over three times as likely, respectively, to have been actually placed in a mental health program in the CYA. They were also much more likely to have been prescribed psychotropic medications.

For females, of those who had one or more of these elevations, $76.7 \%$ had subsequent mental health problem indicators. Still, even female wards with no elevations in these MAYSI scales were more likely than not (58.6\%) to be later identified and/or treated for mental health problems. 
Table 8

Percent with Mental Health Intervention Indicators

By Number of Treatment-relevant MAYSI Elevations ${ }^{\mathrm{a}}$ and Gender

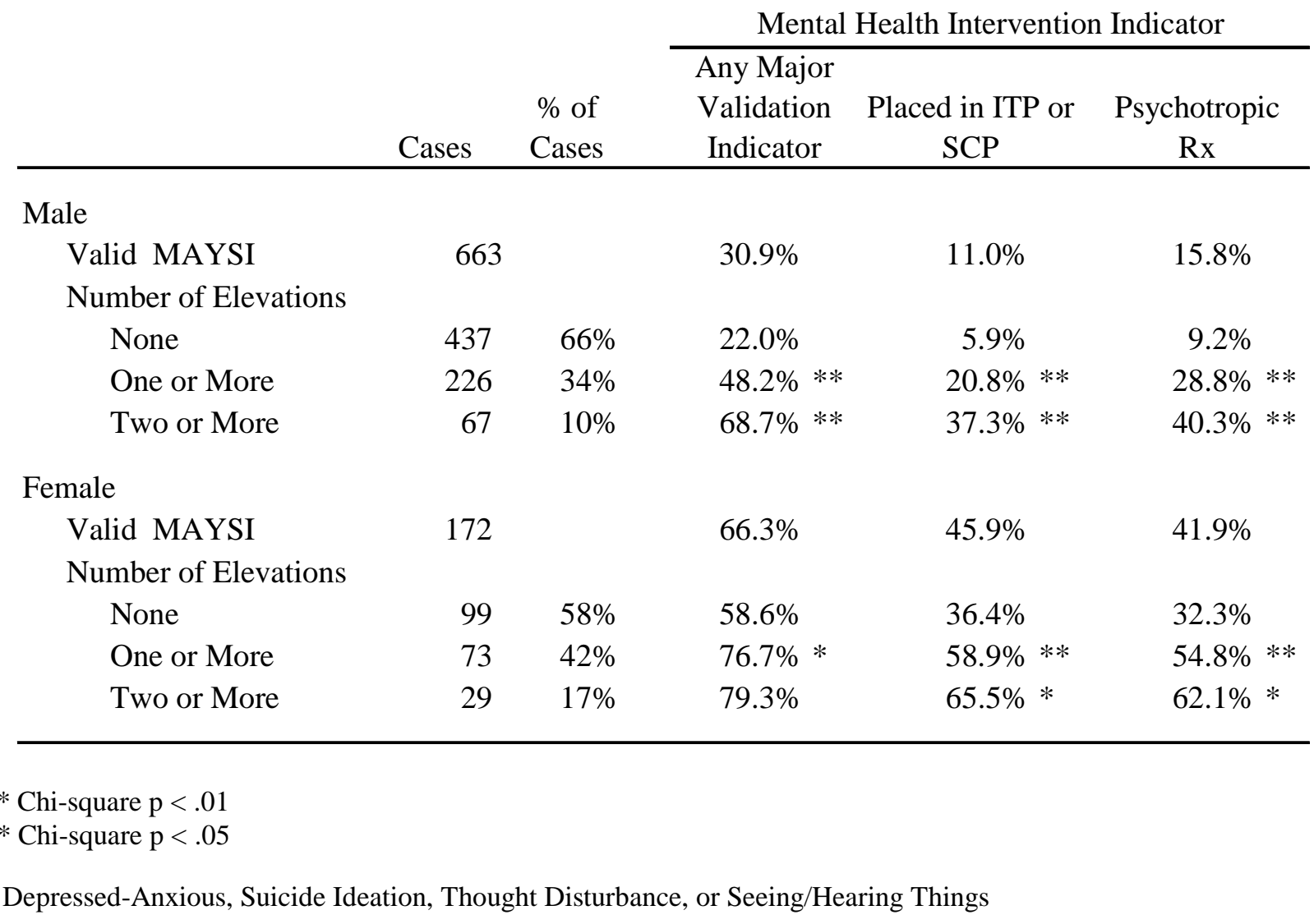

Roughly a third of these young women were placed in mental health units and/or provided psychotropic medications.

\section{$\underline{\text { False Positive and False Negative Errors }}$}

The foregoing suggests that these MAYSI scales can identify smaller groups of wards who have a higher likelihood of needing mental health interventions later on. These instruments, then, have some value as a "back-up" component to other diagnostic processes at the reception centers. Clearly, however, some wards who had no elevated scores received mental health interventions 
(false negatives) and many who had elevations did not receive interventions (false positives). A large number of false positive errors could make the back-up identification process inefficient and expensive. Further, the magnitude of both kinds of errors will reduce the value of these instruments for describing and estimating the overall level of treatment need in the population.

Table 9 shows the number and types of errors that occur when these combinations of scales are used to identify wards receiving subsequent mental health intervention. True Positives comprised $16.4 \%$ of the male sample and True Negatives comprised another $52.4 \%$ of the sample. Together, $68 \%$ of the males were correctly identified by this criterion. This criterion was wrong for about $32 \%$ of the sample: $17.6 \%$ False Positives and $14.5 \%$ False Negatives. False positive errors (over-prediction errors) were expected. Screening devices are intended to be "sensitive" in order to avoid missing too many wards who may need intervention. False negative errors are more troubling, as they suggest that the process cannot identify wards who do need intervention. Almost half (96 of 205 , or $47 \%$ ) of wards who received mental health interventions had no elevations on these scales. Additional analysis (not shown) found that these errors occurred mostly for those wards whose interventions involved suicide screening, staff observations, or placement on waiting lists for programs-indicators of need that tended to occur "later" in the wards' stays and/or which were less indicative of immediate need of mental health intervention. The scales were able to identify the more proximal and more intensive interventions (placement in mental health programs) nearly two-thirds $(64 \%)$ of the time.

For females, the use of these scale elevations resulted in correct predictions only $56 \%$ of the time. Only $42 \%$ of the sample had any of these scale elevations, well below the $66 \%$ who were actually identified to receive intervention. As a result, while there were relatively few false 
Table 9

Percent with Mental Health Intervention Indicators

Correctly Identified by Treatment-relevant MAYSI Elevations ${ }^{\mathrm{a}}$

by Gender

\begin{tabular}{|c|c|c|c|c|c|c|}
\hline & \multirow{2}{*}{\multicolumn{2}{|c|}{$\begin{array}{cc} & \% \text { of } \\
\text { Cases } \quad \text { Cases }\end{array}$}} & \multicolumn{4}{|c|}{ Any Major Mental Health Intervention Indicator } \\
\hline & & & & No & & Yes \\
\hline \multicolumn{7}{|l|}{ Male } \\
\hline Valid MAYSI & 663 & $100 \%$ & 458 & $69.1 \%$ & 205 & $30.9 \%$ \\
\hline No Major Elevations & 437 & $66 \%$ & 341 & $\mathbf{5 1 . 4 \%}$ True Neg & 96 & $14.5 \%$ False Neg \\
\hline One or More & 226 & $34 \%$ & 117 & $17.6 \%$ False Pos & 109 & $16.4 \%$ True Pos \\
\hline Correctly Identified & & $68 \%$ & & $51.4 \%$ & & $16.4 \%$ \\
\hline \multicolumn{7}{|l|}{ Female } \\
\hline Valid MAYSI & 172 & $100 \%$ & 58 & $33.7 \%$ & 114 & $66.3 \%$ \\
\hline No Major Elevations & 99 & $58 \%$ & 41 & $\mathbf{2 3 . 8 \%}$ True Neg & 58 & $33.7 \%$ False Neg \\
\hline One or More & 73 & $42 \%$ & 17 & $9.9 \%$ False Pos & 56 & 32.6\% True Pos \\
\hline Correctly Identified & & $56 \%$ & & $23.8 \%$ & & $32.6 \%$ \\
\hline
\end{tabular}

${ }^{a}$ Depressed-Anxious, Suicide Ideation, Thought Disturbance, or Seeing/Hearing Things

positives (9.9\% of the sample), there were substantial numbers of false negatives. Over half of the females that received intervention had no elevations on these scales.

These figures suggest that the usefulness of these scales for estimating subsequent mental health treatment interventions in this population is somewhat limited. While the substantial number of false positives was expected as a "cost" of sensitivity, they reduce the efficiency of the instrument as part of a diagnostic process. Among the males, where mental health interventions are not as prevalent, most of those with elevations on these scales did not receive mental health intervention subsequently. Under these circumstances, the CYA's practice of conducting very brief interviews and file reviews to determine the need for further evaluation would appear to be appropriate. This layered approach mitigates the inefficiency and potential expense of over- 
reliance on these instruments. The approach may serve as a model for others who may use these instruments for mental health screening.

For estimating mental health treatment needs in this population, the high number of false negatives appears to undermine the usefulness of the instrument. The up-front screening was able to identify most wards who were placed in mental health programs, but was less accurate in identifying wards who were only treated with medications or whose treatment needs were determined later during their stays. Further, as discussed earlier, the indicators of treatment intervention need used in this study were somewhat ambiguous. In order to determine the usefulness of these instruments for estimating mental health treatment needs, a more direct measure of that need would be required. That research is currently being conducted.

\section{$\underline{\text { Substance Abuse and Mental Health Co-morbidity }}$}

Substance abuse is considered a major problem for these young offenders in and of itself. It is also felt to complicate the treatment of mental health problems. Drug and alcohol abuse may contribute to mental health problems and/or it may be an attempt at self-medication. In either case, a positive relationship between substance abuse and mental health problems would be expected. The issue here is whether self-reported substance abuse, alone or in combination with reported mental health symptoms, helps to identify wards with mental health problems leading to subsequent identification and/or intervention. These relationships are shown on Table 10.

Included in this co-morbidity analysis are those cases with valid scales on both the MAYSI and the Drug Experience Questionnaire (DEQ). Because of the DEQ's somewhat more stringent validity criteria, there are 150 fewer cases included than in the analysis of the MAYSI. The results indicate that substance abuse, as measured by the DEQ does not seem to be related to the 
Table 10

Percent with Mental Health Intervention Indicators

By DEQ and MAYSI Treatment-relevant MAYSI Elevations ${ }^{\mathrm{a}}$ and Gender

\begin{tabular}{|c|c|c|c|c|c|}
\hline & \multirow[b]{2}{*}{ Cases } & \multirow[b]{2}{*}{$\begin{array}{l}\% \text { of } \\
\text { Sample }\end{array}$} & \multicolumn{3}{|c|}{ Mental Health Intervention Indicator } \\
\hline & & & $\begin{array}{l}\text { Any Major } \\
\text { Validation } \\
\text { Indicator }\end{array}$ & $\begin{array}{c}\text { Placed in ITP or } \\
\text { SCP }\end{array}$ & $\begin{array}{c}\text { Psychotropic } \\
\text { Rx }\end{array}$ \\
\hline \multicolumn{6}{|l|}{ Male } \\
\hline Valid DEQ and MAYSI & 513 & & $31.2 \%$ & $11.3 \%$ & $16.6 \%$ \\
\hline \multicolumn{6}{|l|}{ DEQ Substance Abuse Flag } \\
\hline Normal & 128 & $25 \%$ & $21.9 \%$ & $8.6 \%$ & $13.3 \%$ \\
\hline Elevated & 385 & $75 \%$ & $34.3 \% * *$ & $12.2 \%$ & $17.7 \%$ \\
\hline \multicolumn{6}{|l|}{ MAYSI and DEQ } \\
\hline Neither & 95 & $19 \%$ & $17.9 \% * *$ & $7.4 \%$ & $10.5 \%$ \\
\hline Both & 136 & $27 \%$ & $52.2 \% * *$ & $23.5 \% * *$ & $30.9 \% * *$ \\
\hline \multicolumn{6}{|l|}{ Female } \\
\hline Valid DEQ and MAYSI & 135 & & $64.4 \%$ & $43.0 \%$ & $40.7 \%$ \\
\hline \multicolumn{6}{|l|}{ DEQ Substance Abuse Flag } \\
\hline Normal & 38 & $28 \%$ & $57.9 \%$ & $42.1 \%$ & $21.1 \%$ \\
\hline Elevated & 97 & $72 \%$ & $67.0 \%$ & $43.3 \%$ & $48.5 \% * *$ \\
\hline \multicolumn{6}{|l|}{ MAYSI and DEQ } \\
\hline Neither & 24 & $18 \%$ & $58.3 \%$ & $37.5 \%$ & $12.5 \% * *$ \\
\hline Both & 42 & $31 \%$ & $78.6 \%$ & $57.1 \%$ & $61.9 \% * *$ \\
\hline
\end{tabular}

$* *$ Chi-square $\mathrm{p}<.01$

$*$ Chi-square $\mathrm{p}<.05$

${ }^{\mathrm{a}}$ Depressed-Anxious, Suicide Ideation, Thought Disturbance, or Seeing/Hearing Things

kinds of mental health indicators considered in this analysis. While the percentages with subsequent mental health interventions was higher for those with elevated scores on the DEQ, these differences were not substantial. Statistically significant relationships were found only for the general (“Any”) indicator for males and for psychotropic medications for females.

Combinations of DEQ elevations and elevations on one or more of the four treatment-relevant MAYSI scales were not much better than simply using any elevation on the MAYSI scales alone. For males, narrowing the criteria in this way reduced the identified group by 90 cases or 14\% 
(136 cases vs. 226 cases). Among this smaller group there were only slightly higher percentages of wards who had mental health intervention indicators. A similar result was found for females.

\section{Prior Criminal Behavior}

Prior criminal behavior patterns of wards entering state-level incarceration seem particularly relevant for understanding their mental health status. It is often assumed that wards with extremely extensive or violent criminal careers would be more likely to suffer from mental health problems requiring treatment. If so, this information could perhaps be combined with assessment information to identify wards most in need of mental health services. This possibility was explored by assessing the relationship between prior arrests and the indicators of mental health intervention. Wards were categorized by the number of arrest charges they had prior to their commitment to the CYA and by the number of violent arrest charges.

Unfortunately, this information was not helpful in identifying wards in need of mental health services. Neither total prior offense charges nor violent prior offense charges was related to mental health interventions. In addition, information on prior criminal behavior was not helpful in combination with TNA scores for creating categories of wards with greater than average likelihood of mental health intervention. Percentages with interventions for these subgroups were close to the percentages when priors were not included, and no trends were observed. Because the interest was in establishing easily identified groups based on prior record and TNA scores, no attempt was made to develop prediction equations (e.g., using logistic regression models) that would weight the contributions of these scales and priors to achieve the best predictions. These kinds of analysis will be performed when additional diagnostic data become available for this sample in the near future. 
This document is a research report submitted to the U.S. Department of Justice. This report has not been published by the Department. Opinions or points of view expressed are those of the author(s) and do not necessarily reflect the official position or policies of the U.S. Department of Justice. 


\section{Discussion}

Overall, MAYSI Scales and YSR Scales were related to validation criteria in expected ways. Wards with high scores on these instruments tend to come to the attention of mental health personnel to a greater extent than those who do not score high. For screening purposes, these individual scales can be helpful for identifying wards who may require mental health intervention at some point during their institutional stay. Those scales that measure attitudes and experiences along the lines of traditional mental health concerns (depression, anxiety, strange thoughts, etc.) were most useful in this regard. These instruments cannot replace one-on-one evaluations, however, and the CYA's practice of using these scores as a back-up to standard clinical methods may serve as model to others. Brief interviews and file reviews triggered by high scores on certain scales could help identify wards who were unwilling to report problems in face-to-face interviews. These practices are relatively inexpensive and can be accomplished very quickly after receiving the results of the assessment.

Of the two instruments, the MAYSI, which was developed specifically for this kind of screening, performed better. Wards with elevated scores on various MAYSI scales were more likely to receive mental health intervention than were wards with elevations on similar YSR scales. These results are consistent with the clinical observations of psychological staff at the reception centers and program institutions, who felt the YSR results were not as useful as the MAYSI results. The MAYSI results were felt to more clearly match their own professional judgment of the wards' mental health statuses, whereas the YSR results were felt to understate 
the wards' levels of disturbance. It is not surprising, then, that the MAYSI would be better able to predict placement decisions based on these clinical judgments.

Certain combinations of scales may provide a basis for increasing the efficiency of these instruments, particularly for males. These scales identified subsets of wards with relatively high probabilities of subsequent mental health intervention. Wards with elevations on scales measuring Depressed-Anxious feelings, Suicide Ideation, or Thought Disturbance (including reports of Seeing/Hearing Things) represented a group with a relatively high probability of later mental health intervention. These combinations of serious problems, particularly the presence of suicidal thoughts or serious thought problems, suggest the need for more immediate intervention and may indicate the need for more intensive treatment.

The addition of information on criminal behavior patterns and substance abuse was not helpful in identifying wards with subsequent mental health treatment needs. More extensive patterns of criminal behavior or violent behavior did not distinguish wards who needed mental health services from those who did not. Further, while there was considerable overlap between reported mental symptoms and reported substance abuse patterns, the combination of these problems did not increase the likelihood that wards would receive subsequent mental health intervention. The sheer volume of crimes, especially violent crimes committed by these wards, however, and the extensive histories of substance abuse found in this population serve as cogent reminders that these young people are experiencing difficulties along a number of important domains simultaneously. These interlocking multiple deficits complicate the development and implementation of programs focused on any one of them.

Both the MAYSI and the YSR appeared to work better for males than for females. Neither instrument was as helpful for identifying female wards who received attention for mental health 
problems as they were for males. Further, neither instrument reflected the wide disparity in mental health intervention between female and male wards. Youth Authority clinicians have observed for some time that female wards have a much higher prevalence of serious mental health problems and have successfully argued for a greater availability of mental health services for female wards. These differences, however, were not reflected in the percentages with elevations on either the MAYSI or the YSR. Further, elevations on these instruments did not differentiate as effectively for females between those who received intervention and those who did not. It would appear that these paper-and-pencil questionnaires may not work as effectively for identifying mental health intervention needs for the female wards in this population.

It is also possible, however, that these "service" measures are not as valid for females as indicators of mental health intervention needs. Because there are more resources and services available for females, there may be a greater tendency to use these resources for female wards with less severe (or more transient) problems. In other words, the indicators of mental health intervention may mean somewhat different things for male and female wards. More research is needed on this issue.

An important next step will be to examine the performance of these instruments in terms of their ability to identify wards with acute mental health problems, rather than in terms of referral for treatment. Treatment decisions may take factors into account other than the mental health status of the wards. Such factors may include the availability of services at each site, other problems the ward may be experiencing, or the ward's behavior. For example, sex offender programs have more psychological treatment resources, and wards in these programs who have other mental health problems may be maintained on those programs rather than referred to Intensive Treatment Programs or Specialized Counseling Programs. These screening instruments 
should also be evaluated relative to actual diagnosis and the diagnosis/treatment interface. Research on these issues is currently underway.

\section{Limitations of the Present Study}

The present study was limited in its scope. The underlying issue is the validity of the instruments currently in use by the CYA for mental health screening. Validity would be indicated by a strong association between these measures and direct indicators of mental health problems warranting treatment. No such indicators were available. As an approximation of this need for treatment, this study used indicators of actual intervention: placement in mental health programs, prescriptions for psychotropic medications, and actions (e.g., placement on waiting lists) that indicate that these interventions would have been made if resources were available. However, some wards are placed in programs simply for evaluation or for reasons other than traditional mental health problems (e.g., violent offenders). Conversely, wards with mental health problems may not be treated in one of these ways (e.g., mentally ill sex offenders may be treated in sex offender programs). These limitations reduce the correspondence between these indicators and mental health treatment need.

In addition, the sample, which was demographically representative of the larger population of CYA admissions, excluded $142(14.5 \%)$ of the wards, who were not administered the paper-andpencil assessment battery, due to scheduling problems at the clinics. No detailed information was available on these wards, but it is possible that these scheduling problems could have been related to mental health or behavioral issues (e.g., wards placed in lock-up). The exclusion of these wards may have biased the sample toward fewer mental health problems to some unknown extent. 


\section{References}

Abt Associates, Inc. (1994). Conditions of confinement: Juvenile detention and corrections

facilities. Office of Juvenile Justice and Delinquency Prevention: Washington, DC.

Achenbach, T. (1991). Manual for the Youth Self-Report and 1991 Profile, Burlington, VT:

University of Vermont Department of Psychiatry.

American Psychiatric Association. (1994). DSM IV: Diagnostic and Statistical Manual of Mental

Disorders (4th). Washington, D.C.: American Psychiatric Association.

Bartol, C. and Bartol, A. (1989). Juvenile delinquency: A systems approach. Englewood Cliffs, NJ: Prentice Hall.

Blumstein, A., Cohen, J., Roth, J., and Visher, C. (Eds.) (1986). Criminal Careers and Career Criminals. Washington, DC: National Academy Press.

Burns, B., Hoagwood, K., and Mrazek, P. (1999). Effective treatment for mental disorders in children and adolescents. Clinical Child \& Family Psychology Review, 2(4), 199-254.

Cauffman, E., Feldman, S., Waterman, J., and Steiner, H. (1998). Posttraumatic Stress disorder among female juvenile offenders. Journal of the American Academy of Child and Adolescent Psychiatry, 37(11), 1209-1216.

Eronen, M., Angermeyer, M., and Schulze, B. (1998). The psychiatric epidemiology of violent behaviour. Social Psychiatry \& Psychiatric Epidemiology, 33(Suppl 1), S13-S23.

Garbarino, J. (1995). Raising children in a socially toxic environment. 1st ed. San Francisco, CA: Jossey-Bass.

Gottfredson, M., and Hirschi, T. (1990). A general theory of crime. Stanford, CA: Stanford University Press. 
Griffin, P. (2000) Assessing detained youth in Pennsylvania. Juvenile Justice Advisory

Committee, Pennsylvania Commission on Crime and Delinquency. Report available at: http://www.pccd.state.pa.us/PUBS/PROGRESS/dec2000.pdf.

Grisso, T., and Barnum, R. (2000). Massachusetts Youth Screening Instrument-Second Version: User's manual and Technical Report. Worcester, MA: University of Massachusetts Medical School.

Grisso, T., Barnum, R., Fletcher, K., Cauffman, E., and Peuschold, D. (2001). Massachusetts Youth Screening Instrument for mental health needs of juvenile justice youths. Journal of the American Academy of Child \& Adolescent Psychiatry, 40, 541-548

Haapanen, R. (1990). Selective incapacitation and the serious offender: A longitudinal study of criminal career patterns. New York: Springer-Verlag.

Haapanen, R. (2000). Mental health and substance abuse treatment needs assessment: Description and preliminary findings. California Youth Authority

Hagell A (2002) The mental health of young offenders. Bright Futures: Working with vulnerable young people. London: Mental Health Foundation. Report available at: http://www.mentalhealth.org.uk/html/content/young_offenders.pdf).

Herz, D. and Poland, A. (2002). Assessing the need for and availability of mental health services for juvenile offenders. Report to the Nebraska Commission on Law Enforcement and Criminal Justice. Report available at: http://www.nol.org/home/crimecom/Documents.htm Mulvey, E. (1994). Assessing the evidence of a link between mental illness and violence. Hospital and Community Psychiatry, Vol. 45, 663-668. 
Maryland Department of Juvenile Justice (2001). Mental health and substance abuse programming enhancements in the juvenile justice system: A three year planning and budget strategy. Report available at: http://www.dji.state.md.us/pdf/mhsa2001.pdf

Shelton, D. (1998). Estimates of emotional disorder in detained and committed youth in the Maryland Juvenile Justice System. Report to the Maryland Juvenile Justice Advisory Council.

Schoenwald, S. and Hoagwood, K. (2001). Effectiveness, transportability, and dissemination of interventions: What matters when. Psychiatric Services, 52(9), 1190-1197.

Steadman, H., and Cocozza, J. (1978). Selective reporting and the public's misconceptions of the criminally insane. Public Opinion Quarterly, Vol. 41 (4), 423-533.

Steiner, H. (1997). Practice parameters for the treatment of conduct disorders. Journal of the American Academy of Child and Adolescent Psychiatry. 36 (10) Supplement.

Steiner H., Cauffman E, and Duxbury E. (1999) Personality traits in juvenile delinquents: relation to criminal behavior and recidivism. Journal of the American Academy of Child and Adolescent Psychiatry 38 (3): 256-262.

Steiner, H., Garcia, I., and Matthews, Z. (1997). Posttraumatic stress disorder in incarcerated juvenile delinquents. Journal of the American Academy of Child and Adolescent Psychiatry, 36 (3) $357-365$.

Steiner H., Williams, S., Benton-Hardy, L., Kohler, M., Duxbury, E. (1997). Violent crime paths in incarcerated juveniles: psychological, environmental, and biological factors. In: Raine, A, Farrington, D, Brennan P, and Mednick, S (Eds) The Biosocial Bases Of Violence. New York: Plenum. 
Stewart, D.G. \& Trupin, E.W. (2003). Clinical utility and policy implications of a statewide mental health screening process for juvenile offenders. Psychiatric Services, 54(3), 377-382.

Schwank, J., Esponosa, E, and Tolbert, V. (2003). Mental health and juvenile justice in Texas.

Texas Juvenile Probation Commission. Report available at:

http://www.tjpc.state.tx.us/publications/reports/Mental\%20Health\%20Report.pdf

Tinklenberg, J., Steiner, H., Huckaby, W., and Tinklenberg, J. (1996). Criminal recidivism predicted from narratives of violent juvenile delinquents. Child Psychiatry and Human Development, 27(2), 69-79.

Ulzen, T., Hamilton, H. (1998). The nature and characteristics of psychiatric comorbidity in incarcerated adolescents. Canadian Journal of Psychiatry, 43(1), 57-63.

Weinberger D. (1997). Distress and self restraint as measures of adjustment across the life span: Confirmatory factor analyses in clinical and non-clinical samples. Psychological Assessment, 9, 132-135.

Weinberger, D. and Schwartz, G. (1990). Distress and restraint as superordinate dimensions of self-reported adjustment: A typological perspective. Journal of Personality, 58, 381-417.

Winters, K. and Henly, G. (1989). Personal experience inventory (PEI) test and manuals. Los Angeles, CA: Western Psychological Services. 


\section{Appendix A \\ Instruments Included in the Study}

\section{$\underline{\text { Achenbach Child Behavior Checklist--Youth Self Report (YSR) }}$}

The YSR, designed by Thomas Achenbach (University of Vermont) in 1989 and revised in 1991 (Achenbach, 1991), determines if wards have mental health problems by obtaining their views of their own functioning. It focuses on general psychopathology as well as resilience factors (ego strength). It also indicates how the ward may manifest problems, either through “internalizing" (e.g., anxiety or depression) or "externalizing” (e.g., aggressiveness or acting out) disorders. The YSR is widely used at Community Mental Health Centers in California.

The instrument was developed by identifying items that best discriminated between youths who were referred for mental health treatment and those who were not. High scores on scales indicate the extent to which youth answer the questions similarly to youth in the referred samples. The YSR was designed for adolescents ages 11 to 18 with at least a fifth-grade reading level and takes approximately 30 minutes to administer. Each question offers three answers: not true (0), somewhat or sometimes true (1), and very true or often true (2). Scales are created by adding the scores for each item.

Internalizing Scales measure problems the ward is manifesting internally:

\section{Withdrawn}

\section{Somatic Complaints}

\section{Anxiety/Depression}

Externalizing Scales measure behaviors that indicate external responses to problems:

\section{Delinquent Behavior}

Aggressive Behavior 
The YSR also includes three other problem scales:

Social Problems

Thought Problems

Attention Problems

Massachusetts Youth Screening Instrument: Second Version (MAYSI)

This instrument was developed by Thomas Grisso and others at the University of Massachusetts specifically for use in the juvenile justice system. It was designed as a screening instrument to identify youths at risk of serious mental or emotional disorder and those in need of clinical intervention (Grisso, Barnum, Fletcher, Cauffman, and Peuschold, 2001). The MAYSI assesses various types of mental/emotional disturbance or distress that might indicate a youth is at risk for mental disorder. Like the YSR, it measures symptoms rather than disorders. The MAYSI requires a sixth grade reading level and approximately twenty minutes to administer. It consists of 52 yes/no questions. Unless otherwise indicated, all questions ask about experiences within the past few months. MAYSI scales include:

Alcohol-Drug Use

Angry-Irritable

Depressed-Anxious

Somatic Complaints

Suicide Ideation

Thought Disturbance (Boys only)

Traumatic Experiences 
The Youth Authority does not use the Alcohol-Drug Use scale of this instrument because the battery includes a more comprehensive measure of substance abuse problems (the Drug Experience Questionnaire, described below).

\section{Drug Experience Questionnaire (DEQ)}

The DEQ provides a standardized screening tool for identifying adolescents and young adults who may benefit from drug treatment. It consists of 30 items which read at the fourth grade level. The DEQ scales are:

\section{Problem Severity}

\section{Defensiveness}

\section{Infrequency}

Problem Severity scores reflect the extent to which the individual is psychologically and behaviorally involved with drugs. High scores suggest symptoms indicative of drug dependence and abuse, such as use in multiple settings, loss of control, and restructuring of activities to accommodate drug use.

The Defensiveness and Infrequency scales are designed to identify wards who minimize (Defensiveness) or exaggerate (Infrequency) their substance abuse problems. They are intended to identify wards who may deliberately try to manipulate the screening process to get referred into (or avoid) mental health or substance abuse programs. 
This document is a research report submitted to the U.S. Department of Justice. This report has not been published by the Department. Opinions or points of view expressed are those of the author(s) and do not necessarily reflect the official position or policies of the U.S. Department of Justice. 


\section{Appendix B \\ Medications Indicating Mental Health Intervention}

Use

Generic Name

Trade Name

Anxiety

Bipolar Disorders

$\begin{array}{ll}\text { Diazepam } & \text { Valium } \\ \text { Clonazepam } & \text { Klonopin } \\ \text { Buspirone } & \text { BuSpar } \\ \text { Hydroxyzine } & \text { Vistaril }\end{array}$

Lithium

Lithium

$\underline{\text { Depression }}$

Sertraline

Zoloft

Trazadone

Amitriptyline

Desyrel

Elavil

Paroxetine

Paxil

Doxepin

Sinequan

Nortriptyline

Pamelor

Imipramine

Tofranil

Nefazaodone

Serzone

Bupropion

Fluoxetine

Wellbutrin

Prozac

Desipramine

Norpramin

Fluvoxamine

Luvox

Venlafaxine

Effexor

$\underline{\text { Mood Stabilizers }}$

Divalproex

Carbamazepine

Depakote

Tegretal

Psychotic Symptoms

$\begin{array}{ll}\text { Olanzapine } & \text { Zyprexa } \\ \text { Loxapine } & \text { Loxitane } \\ \text { Haloperidol } & \text { Haldol } \\ \text { Risperidone } & \text { Risperdal } \\ \text { Thioridazine } & \text { Mellaril } \\ \text { Thiothixene } & \text { Navane } \\ \text { Trifluoperazine } & \text { Stelazine } \\ \text { Chlorpromazine } & \text { Thorazine }\end{array}$

